\title{
Westinghouse Multi-Annular Swirl Burner CRADA 95-029 Final Report
}

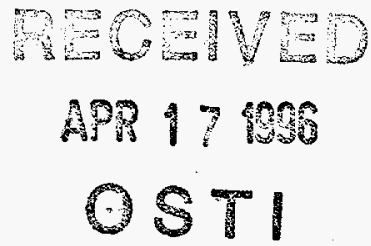

June 1995

\author{
U.S. Department of Energy \\ Office of Fossil Energy \\ Morgantown Energy Technology Center \\ 3610 Collins Ferry Road \\ Morgantown, WV 26505
}

and

Westinghouse Electric Corporation

1310 Beulah Road

Pittsburgh, PA 15235

\section{DISCLAIMER}

\begin{abstract}
This report was prepared as an account of work sponsored by an agency of the United States Government. Neither the United States Government nor any agency thereof, nor any of their employees, makes any warranty, express or implied, or assumes any legal liability or responsibility for the accuracy, completeness, or usefulness of any information, apparatus, product, or process disclosed, or represents that its use would not infringe privately owned rights. Reference herein to any specific commercial product, process, or service by trade name, trademark, manufacturer, or otherwise does not necessarily constitute or imply its endorsement, recommendation, or favoring by the United States Government or any agency thereof. The views and opinions of authors expressed herein do not necessarily state or reflect those of the United States Government or any agency thereof.
\end{abstract}





\title{
Westinghouse Multi-Annular Swirl Burner CRADA 95-029 Final Report
}

June 1995

\author{
U.S. Department of Energy \\ Office of Fossil Energy \\ Morgantown Energy Technology Center \\ 3610 Collins Ferry Road \\ Morgantown, WV 26505 \\ and
}

Westinghouse Electric Corporation

1310 Beulah Road

Pittsburgh, PA 15235 



\section{DISCLAIMER}

Portions of this document may be illegible in electronic image products. Images are produced from the best available original document. 



\title{
Westinghouse Multi-Annular Swirl Burner CRADA Einal Report
}

\author{
Morgantown Energy Technology Center \\ Westinghouse Electric Corporation
}

\author{
June 14,1995
}

\subsection{ABSTRACT}

The FLUENT computational fluid dynamic code has been used to aid design of the Westinghouse Multi-Annular Swirl Burner (MASB). After successful comparison of FLUENT predictions to test data, design studies using FLUENT have indicated that backwall holes are unnecessary in the MASB design. FLUENT was then used to study the adaptation of the MASB design to the Power systems Development Facility (PSDF). Preliminary steady-state and transient simulations of the propane-fueled start-up process indicate that flame structure is dependent on the choice turbulence closure and the resultant variation in swirl levels and recirculation zones. Due to the effect of duct geometry on swirl dissipation, a more accurate representation of the transition duct connecting the MASB to the turbine will be needed to better describe the flame structure.

\subsection{INTRODUCTION}

Funding issues have delayed, if not cancelled, all but two of the 18-inch MASB hardware tests at the University of Tennessee Space Institute (UTSI). In these two tests, which were performed in June and July of 1994, there were indications that the natural gas performance of the combustor required improvement.

The MASB dual fuel capability, i.e. the ability to burn a high heating value fuel as well as the low energy syngas, is critical to successful operation of the Power systems Development Facility (PSDF). In addition, dual fuel capability is necessary to ensure the commercial viability of the Pressurized Fluid-Bed combustion technology, of which the MASB is a key component. Firing a high heating value gas, such as methane or propane, is required during plant start up and other off-design conditions.

Contract funding limitations, coupled with the importance of the MASB performance using high heating value fuels, are driving the use of computer simulations to aid in the successful completion of hardware development. The simulations are used to model the major aspects of MASB performance, including chemical reactions, fluid mechanics, and heat transfer. In a complex application such as the MASB, computational modeling is not at the stage where it can completely replace hardware tests. However, once predictions have been verified in a specific configuration there 
is a high degree of confidence in the ability of computational models to show trends and qualitatively describe the flow field.

\subsection{Objective and Scope of the CRADA}

There are two principal objectives of this CRADA. The first is to combine the computational expertise at METC with the design and test information of Westinghouse to help improve the design of the 18-inch MASB. The second is to further validate the FLUENT (Fluent, Inc., Lebanon, NH) commercial computational fluid dynamic (CFD) code as applied to complex, highly swirling, reacting flows. The greater our confidence in such computational models, the more effectively they can be used to improve the performance of METC technologies while reducing time and costs required to bring systems to commercial scale.

Westinghouse, the technology supplier for the MASB, is concerned about burner performance while firing high heating value fuels. The high heat release and the low flow rates associated with this type of operation have yet to be fully tested. Of particular concern is the cold start condition for which no hardware tests have been run.

Under the CRADA, METC has performed FLUENT simulations for three test configurations of the 18-inch MASB. These simulations are all two-dimensional, axisymmetric models studying burner performance when firing methane or propane. Three different hardware configurations have been simulated to gauge the effect of proposed changes on burner performance. A detailed statement of work is part of the CRADA agreement and can be found in the Appendix of this report.

\subsection{Model Description}

The computational model is designed to simulate the 18-inch MASB in terms of fluid mechanics, conductive and convective heat transfer, and reduced chemical kinetics describing combustion. Three turbulence closures are available in the FLUENT code, namely the $k-\epsilon$ closure, the renormalization-group theory (RNG) based model, and the full Reynolds stress model (RSM). All three closures have been used in this work to help determine their relative accuracy and the practicality of their use for MASB modeling.

The simplest and most computationally robust turbulence model is the $k-\epsilon$. This model has been found to be less accurate for highly swirling flows but its simplicity makes it a good first choice. The RSM model was also used since it will yield more accurate results for the anisotropic, highly swirling flows encountered in the MASB. This was done even though the RSM requires significantly more computational time than the $k-\epsilon$. 
Since the $k-\epsilon$ solution is used as a starting point for the RSM simulation, very little additional setup work is required to perform a comparison of the results. The RNG model, which is touted to have the accuracy of the RSM closure with the speed of the $k-\epsilon$ closure, was also used for some simulations. This was done with the expectation that the speed and accuracy of the RNG closure would be necessary for transient simulations.

Previous simulations of the 14-inch MASB indicated that the 3-D simulation offers no significant improvement in modeling accuracy over the 2-D simulation. Considering the considerable time involved in performing 3-D simulations for reacting flows, and the limited resources available, Westinghouse and METC decided to perform only 2-D simulations as part of this 18-inch MASB CRADA.

Combustion chemistry was modeled using the generalized finite rate formulation for turbulent flows as described in Fluent, Inc. (1995). The reaction rates are determined using either Arrhenius rate expressions or by using an 'eddy breakup model', whichever proves to be the limiting (slowest) rate. The eddy breakup model relates the reaction rate to the dissipation of the turbulent eddies containing reactants and products. The simulations considered the following chemical species: $\mathrm{N}_{2}$, either $\mathrm{CH}_{4}$ or $\mathrm{C}_{3} \mathrm{H}_{8}$ depending on fuel, $\mathrm{CO}, \mathrm{O}_{2}, \mathrm{CO}_{2}$, and $\mathrm{H}_{2} \mathrm{O}$. Transport equations for each species except $\mathrm{N}_{2}$ were solved. Local $\mathrm{N}_{2}$ concentrations are calculated by balance, from the sum of all other species concentrations. The following simplified set of combustion reactions was used to describe reactions involving these species (Westbrook and Dryer, 1981; Coffee, 1985; Hautman, et al. 1981):

$$
\mathrm{CH}_{4}+1.5 \mathrm{O}_{2}+\mathrm{CO}+2 \mathrm{H}_{2} \mathrm{O}
$$

or

$$
\mathrm{C}_{3} \mathrm{H}_{8}+3.5 \mathrm{O}_{2} \rightarrow 3 \mathrm{CO}+4 \mathrm{H}_{2} \mathrm{O} \quad,
$$

depending on fuel type, and

$$
\mathrm{CO}+0.5 \mathrm{O}_{2} \rightarrow \mathrm{CO}_{2}
$$

The Arrhenius reaction rate for reaction (1) is given by

$$
k_{1}=A_{1} \exp \left(E_{1} / R / T\right)\left[C_{4}\right]^{-0.3}\left[O_{2}\right]^{1.3}
$$

where $k_{1}$ is the reaction rate in $\mathrm{kg}-\mathrm{mole} / \mathrm{m}^{3} / \mathrm{s} ; A_{1}=2.8 \mathrm{E} 91 / \mathrm{s}$; 
$\mathrm{E}_{1} / \mathrm{R}=24360 \mathrm{~K}$; and with $\left[\mathrm{CH}_{4}\right]$ and $\left[\mathrm{O}_{2}\right]$ denoting local concentrations of $\mathrm{CH}_{4}$ and $\mathrm{O}_{2}$ respectively in $\mathrm{kg}-\mathrm{mole} / \mathrm{m}^{3}$.

The Arrhenius reaction rate for reaction (2) is given by

$$
k_{2}=A_{2} \exp \left(E_{2} / R / T\right)\left[C_{3} H_{8}\right]^{0.1}\left[O_{2}\right]^{1.65}
$$

where $A_{2}=5.62 \mathrm{E} 9\left(\mathrm{~m}^{3} / \mathrm{kg} \text {-mole }\right)^{0.75} 1 / \mathrm{s}$ and $E_{2} / \mathrm{R}=15098 \mathrm{~K}$.

The Arrhenius reaction rate for reaction (3) is given by

$$
\mathrm{k}_{3}=\mathrm{A}_{3} \exp \left(\mathrm{E}_{3} / \mathrm{R} / \mathrm{T}\right)[\mathrm{CO}]\left[\mathrm{O}_{2}\right]^{0.25}\left[\mathrm{H}_{2} \mathrm{O}\right]^{0.5}
$$

where $A_{3}=2.249 \mathrm{E} 12\left(\mathrm{~m}^{3} / \mathrm{kg} \text {-mole }\right)^{0.75} 1 / \mathrm{s}$ and $E_{3} / R=20130 \mathrm{~K}$.

The reaction describing dissociation of $\mathrm{CO}_{2}$ to yield $\mathrm{CO}$ and $\mathrm{O}_{2}$ has been neglected in this work. Previous. MASB modeling studies comparing predictions to measurement indicted an overabundance of CO was predicted when this reaction was included. Justification for neglecting this reaction can be found in Glassman (1977) which indicates that less than $1 \%$ dissociation of $\mathrm{CO}_{2}$ will occur at the pressures and temperatures observed in this MASB application.

According to Fluent, Inc. (1995), the inclusion of the kinetic rate expression in turbulent combustion serves as a 'cut-off' to the eddy breakup rate when the kinetic rate is very slow. However in most practical combustion situations, the eddy breakup rate is usually much slower than the Arrhenius rate, thus serving as the limiting rate. 


\subsection{RESULTS AND DISCUSSION}

The CRADA Statement of Work (see Appendix) has outlined three MASB configurations that would be modeled. The first configuration is the UTSI design firing natural gas that was tested in June, 1994. The second configuration is the same natural gas-fired UTSI design with sixteen backwall holes designed to modify the burner flow field by reducing the swirl level in the rich zone. The third configuration modeled is the proposed PSDF design firing propane. The results of UTSI and PSDF simulations are discussed in separate sections below.

\subsection{UTSI Simulations}

Natural gas firing of the MASB at UTSI was conducted in June, 1994 where the natural gas was burned in vitiated air

Temperature measurements made during these tests were higher than expected at the downstream sampling rake, with the exception of gas temperatures near the wall. Burner wall temperatures in the rich zone were lower than expected. These results were interpreted to indicate that the flame was stretched out in a long cylindrical form so that the flame did not fill a large part of the burner volume, especially near the burner walls. This flame behavior was felt to result from excessive swirl, which is known to stratify flow. The rich zone swirl number was calculated as 2.76. A sufficiently high swirl number for flame stabilization is normally considered to be 1.0. Based on this analysis, holes were drilled in the backwall of the MASB so that about $25 \%$ of the rich zone vitiated air could enter without swirl, thereby reducing the swirl number to 1.5 . The possible penalty involved in this approach was that combustor wall cooling by swirling gas would probably be reduced. Therefore, the use of backwall holes to modify burner flow patterns was of major concern during the design evaluation.

When the burner with backwall holes was tested on syngas, it functioned very well. An attempt was made to run the modified burner on natural gas after the syngas test, but data were inconclusive consisting of a limited number of exit temperature measurements. These measurements did indicate a different combustion pattern than encountered in previous natural gas tests. This difference resulted from natural gas feeding through the spark ignitor port rather than through the intended Pabst burner ports due to loss of the ignitor rod during the syngas test. In summary, the natural gas tests were inconclusive as to whether the backwall holes represented a design improvement when burning natural gas.

1 Vitiated air properties: $1144 \mathrm{~K}(1600 \mathrm{~F}), 7$ to $10 \mathrm{~atm}$ (103 to $147 \mathrm{psial}$ and 14 to $16 \mathrm{dry}$ vol\% $\mathrm{O}_{2}$ 
The CFD modeling work has since provided important insight into how the MASB functions when burning natural gas in the prototype full size combustor at UTSI. Combustion of $\mathrm{CH}_{4}$ in the UTSI MASB was modeled for burner configurations both with and without backwall holes. The computational domain is illustrated in Figures 1 and 2. The flow of vitiated air and cooling air is specified through each inlet, i.e. the rich zone primary air, the cone cooling air flow, the quench inlet, and the dilution inlet, according to Westinghouse design calculations. Swirl is specified at the appropriate inlets based on the physical geometry of the swirl vanes.

As the first step in the computational study, both the $\mathrm{k}-\epsilon$ and RSM turbulence closures were used to model a natural-gas-fired test performed without backwall holes. The results of these simulations are compared to UTSI measurements in Table I. Comparison of measurement and prediction shows good agreement for both the $\mathrm{k}-\epsilon$ and RSM closures. However, the flow fields predicted by these two models are quite different, as shown in Figure 3 comparing temperature contours and Figure 4 comparing velocity vectors. The RSM model produced flow patterns very similar to those measured in tests using a cold model designed to achieve a similar flow pattern to the hot, full-scale burner.

A hypothetical operating condition was then modeled that was identical to the above case, except for the addition of backwall holes. In two-dimensional axisymetric coordinates, the backwall holes become a backwall 'annular opening'. This annulus was sized to keep the axial velocity through it comparable to the axial velocity expected through the physical holes. The CFD model results clearly show that the effect of the backwall holes was not useful. This is shown in the accompanying plots of temperature and $\mathrm{CO}$ in Figure 5 and Figure 6, respectively. Note that the $\mathrm{CO}$ plot in particular shows that the cylindrical flame located away from the wall which existed in the no-hole case was not replaced by a flame occupying the whole rich zone, but simply by a flame located further downstream.

As a result, the backwall hole concept has been eliminated from the Wilsonville PSDF design. The result should be a better behaved combustor, with maximized wall temperature moderation.

\subsection{Power Systems Development Facility MASB Simulations}

The propane-fuel performance of the PSDF MASB design was studied using FLUENT. Of particular interest to designers is MASB performance at ignition and during the propane-fired start-up process. The start-up process involves increasing fuel and air flows as well as the burner operating pressure and temperature while turbine speed increases over a 70-second time span. 
The higher specific energy content of propane requires lower mass flow rates as compared to syngas for comparable firing rates and unlike syngas, propane is not swirled as it enters the burner. These factors can affect flow patterns within the MASB to produce flow and combustion characteristics different from those experienced during syngas firing. MASB designers are interested in how these factors impact combustion stability and wall temperatures at light-off and during the propane start-up process.

To help answer these questions, both steady-state and transient MASB simulations were performed. These simulations considered more geometric and operational details of the PSDF design than were considered for the UTSI simulations. The computational domain is illustrated in Figure 7 - Figure 9. PSDF design features that are pertinent to start-up performance were incorporated using both standard and customized FLUENT capabilities as follows:

1) the FLUENT porous media model was used to impose loss coefficients across the various burner inlets - these coefficients, which were provided by Westinghouse, determine pressure loss through a region as a function of the square of gas velocity;

2) a FLUENT 'User-Defined-Subroutine' was written to model MASB the swirler regions which would impart a swirl velocity to the inlet air as a function of swirl vane angle and the streamwise gas velocity component;

3) all three turbulence closures, namely $k-\epsilon$, RNG, and RSM, were used for the study;

4) conduction and convection heat transfer was modeled for all metal burner walls interior to the containment vessel, radiative effects were neglected;

5) the duct connecting the MASB to the turbine was assumed to be a constant diameter, cylindrical duct approximately $1.52 \mathrm{~m}$ ( $5 \mathrm{ft}$ ) long.

\section{Initial Condition for Transient Simulations}

An initial condition is required to begin a transient ELUENT simulation. In this application, the burner light-off operating condition was used to create the initial condition. This lightoff condition, represented by operating Point A shown in Table III, was used in a steady-state FLUENT simulation to produce the initial condition. The Point $A$ operating conditions were modeled with all three turbulence closures. In addition to establishing the initial condition, these steady-state 
simulations would validate the pressure drop coefficients and validate the User-Defined-Subroutine model for swirl velocity.

Steady, cold flow simulations were first performed for the three turbulence models. The resultant velocity vectors are shown in Figure 10 - Figure 12. There are significant differences between the $k-\epsilon$ prediction and both the RNG and RSM results, as indicated in these vector plots. The RNG and RSM closures produce a recirculation zone at the burner center line which causes a backflow extending from the burner exit back to the propane inlet. This recirculation was completely absent in the $k-\epsilon$ results. These differences are thought to result from the less dissipative nature of the RNG and RSM closures, allowing for higher swirl levels and resultant increased recirculation.

The predicted air mass flow rates into the burner through the primary, quench, dilution, cone cooling flow, and cylinder cooling flow inlets closely matched those calculated by Westinghouse for operating point $A$. This favorable comparison is shown in Table II which validates the use of the porous media model to replicate the flow resistances of these inlets.

Steady, reacting simulations were then performed at Point $A$ operating conditions for all three turbulence closures. The hot $k-\epsilon$ simulation was produced by igniting the converged cold flow $\mathrm{k}-\epsilon$ results using a high temperature 'patch'. Hot RNG and RSM simulations were then started using the converged, hot, $k-\epsilon$ flow field and then activating the RNG or RSM turbulence model. This technique was used for the RNG and RSM closures knowing it would be difficult to ignite the highly recirculating RSM and RNG cold flow results and expecting that recirculation would decrease for both RSM and RNG simulations under combustion conditions.

Combustion could not at first be established when using the Arrhenius rate constants shown in Section 2.2. Even use of these rate constants at the high 'patch' temperatures ( 2000K) used for light-off, would still produce Arrhenius rates too slow to produce sustained combustion. Self-sustaining combustion was achieved only by lowering the activation energy in each reaction to a very low value of 100 . This allowed the eddy breakup rate to control the reactions.

A converged solution was readily obtained for the steady, hot, k$\epsilon$ closure simulation. Converged results for the corresponding RNG model were much more difficult to obtain, and no converged solution has yet been obtained for the RSM model. Results for each of these cases are shown in Figure 13 - Figure 15. As seen in these figures, the combustion behaviors of the $k-\epsilon$ and RNG results are quite different. The $k-\epsilon$ flame fills the rich zone, with combustion completed at the quench zone. In contrast, the RNG flame is quite elongated, extending down the center line of the combustor. Combustion is not complete until well past the 
dilution zone.

The RSM closure failed to yield a converged solution at operating Point $A$. As seen in the velocity vector plot of Figure 15a, a relatively low pressure area appeared at the center of the rich zone causing inrushing velocities from all directions. Continued iteration failed to eliminate this phenomenon.

For the hot $k-\epsilon$ simulation, Figure 13 a shows that the maximum cooling cone temperature of $524 \mathrm{~K}$ is experienced at the downstream cooling cone edge and the maximum cylinder wall temperature is $507 \mathrm{~K}$ at a point midway down the cylinder section. RNG simulation temperatures illustrated in Figure $14 \mathrm{a}$ show that cooling cone and cylinder wall temperatures are essentially equal to the cooling air temperature. Recall that radiation effects were not included in these simulations.

The extensive recirculation exhibited at the light-off operating condition in both the cold and hot steady flow results caused concern about recirculation problems in the transient

simulations. Steadily increasing air flow rates experienced during the start-up process will produce larger inflows of tangential momentum to the combustion volume. This could result in excessive recirculation and lead to convergence problems and/or non-physical solutions due to entrainment from the exit boundary. To alleviate this problem, the burner outlet was modified to include a 'vortex breaker' section. This was accomplished by converting several computational cells at the exit plane center line to impermeable walls. This configuration is shown in Figure 16.

The steady, hot, $k-\epsilon$, RNG, and RSM simulations were then repeated for operating point $A$ with the vortex breaker in place. For the $k-\epsilon$ simulation, differences in velocity and temperature fields were insignificant for results with and without the vortex breaker. The primary effect of the vortex breaker on the RNG simulation was to slightly decrease the length of a recirculation zone that exists at the center line of the dilution zone.

A significant difference was seen in the RSM results with the vortex breaker in place as shown in Figure $17 \mathrm{a}$ and Figure $17 \mathrm{~b}$. Although computational convergence has not 'yet been reached, it seems that the low pressure region encountered previously has been eliminated. For an accurate comparison to be made, it must be noted that this RSM simulation has experienced $30 \%$ more iterations at higher underrelaxation for all variables than its counterpart without the vortex breaker. Additional work is warranted to study the convergence problems encountered with the RSM model. 


\section{Transient Simulations}

The 70-second start-up process is composed of ten operating points where air flows and temperatures, propane flow, burner exit temperature, and burner pressure are increased to increase turbine speed. These operating points are shown in Table III and Table IV. It was assumed in this work that these ten operating points are distributed uniformly in time over the start-up process, with Point $A$ being the burner light-off condition.

Transient ELUENT simulations were performed to study MASB performance under these time-varying, start-up operating conditions. During the transient simulation, FLUENT boundary conditions were varied to mimic the changes in flows, pressures, and temperatures that would be experienced during the start-up process. The time-dependent boundary conditions were produced by assuming a piecewise-linear variation of all the time-varying operating conditions between the ten operating points comprising the start-up process.

Transient simulations were performed for the $k-\epsilon$ and RNG turbulence closures only. These closures represented the two extremes of burner performance exhibited by both the cold and hot steady-state, light-off simulations discussed above. In addition, the RSM model consumes much more computational time than either the $k-\epsilon$ or RNG model, which is an important concern for transient simulations. The transient simulations were performed assuming the presence of the vortex breaker as discussed in the previous section.

The simulations were performed with a time step of 0.25 seconds. This large time step was necessary because of the relatively long simulated time span ( 70 seconds of MASB operation) to be studied. Due to hardware availability, the runs were limited to approximately 3 days each. Transient iteration parameters were then set based on knowing the physical (CPU) time required per iteration $(\sim 20 \mathrm{~s})$ and the total physical time allowed for the simulation ( 3 days or $2.592 \mathrm{E} 5 \mathrm{~s}$ ). The result was that 50 iterations were allowed per simulation time step. During iterations within each time step, normalized residuals for both $\mathrm{k}-\epsilon$ and RNG models decreased monotonically, reaching nearly identical values at the end of the allotted 50 iterations. However, the normalized pressure residual was on the order of 0.01 for both turbulence closures. Additional work is therefore warranted to study the error induced over time by these relatively large pressure residual errors.

The transient results are best analyzed using the in-house METC animation code. This code is capable of animating transient FLUENT data on a Silicon Graphics platform. A 4mm DAT tape will be sent to Westinghouse that contains the animation code and required data files to allow viewing of the animations. 
The transient $k-\epsilon$ results indicate that the flame region gradually fills the burner during the start-up period. Over the elapsed 70 seconds, the point of complete co burnout moves from the quench zone downstream to the intersection of the burner and the straight exit duct. A high temperature (1700K) toroid of gas forms at the point where the cone cooling air flow enters the rich zone. The highest wall temperature occurs adjacent to this toroid, at the downstream edge of the cooling cone. The wall temperature at this location increases from $524 \mathrm{~K}$ to $749 \mathrm{~K}$ over the 70 second start-up period. At no point during the start-up process were any backflows observed through the burner inlets.

The RNG animation shows that the steady-state flame structure observed at light-off is preserved throughout the transient start-up process. It retains its elongated form centered about the center line, while expanding only slightly before it reaches the exit. Both unreacted $\mathrm{C}_{3} \mathrm{H}_{8}$ and $\mathrm{CO}$ travel down the center of this flame and escape, although less than $0.5 \%$ of the $\mathrm{C}_{3} \mathrm{H}_{8}$ escapes the domain at final flame conditions seen at $t=70$ seconds. Burner walls remain quite cool during the start-up process; seldom are they much hotter than the cooling air temperatures. No backflows occur through burner inlets during the RNG-modeled start-up process. 


\subsection{CONCLUSIONS AND RECOMMENDATIONS}

CFD simulations of the UTSI MASB have indicated that backwall holes do not produce the desired effect on flow and combustion. As a result backwall holes have been eliminated from the PSDF MASB design.

The radiation heat transfer mechanism has not been used in the simulations performed under this CRADA. This effect has been left out intentionally at this stage to reduce computational run times and to simplify the simulation process. However, when comparing the 18-inch MASB predictions to UTSI test data in Table I, it becomes apparent that radiation heat transfer may be playing a significant role in wall heating. For this reason, an additional UTSI combustor simulation with RSM closure is needed. This simulation should include the effects of radiation and then should be compared to the measured wall temperature test data. If use of the radiative heat transfer model significantly reduces the error in the wall temperature prediction, then radiative effects should be included in additional PSDF burner simulations.

Steady-state light-off conditions and the transient start-up process have been modeled for the PSDF MASB design fueled by $\mathrm{C}_{3} \mathrm{H}_{8}$. Simulation results show that burner performance greatly depends on the choice of turbulence closure. The $k-\epsilon$ closure predicts lower swirl levels than the RNG-based simulations, especially in the rich zone. The resultant $k-\epsilon$ flame fills the burner volume, whereas the RNG-modeled flame is elongated, forming a cylinder about the burner center line. This flame structure present in the RNG model, a model which is theoretically more accurate for highly-swirling flows, indicates that poor flame structure could be a concern in the propane-fired PSDF MASB. It should be noted, however, that the fluid mechanic behavior of the combustor is sensitive to the burner outlet duct geometry. Without more detailed information about the burner-toturbine transition duct, it is unclear whether or not the poor flame performance apparent in the simulation will be seen at the PSDF. For this reason the following additional work is recommended:

- Update the outlet geometry of 18-inch MASB to reflect the actual PSDF configuration. The outlet geometry should extend to the turbine inlet. We have not yet been able to obtain sufficient geometric detail to accomplish this.

-Run additional transient simulations of the 18-inch MASB with the accurate PSDF outlet configuration.

Excessive wall temperatures are not observed for either turbulence closure. Follow-up efforts are recommended to investigate and correct difficulties encountered in performing both steady and transient simulations using the RSM turbulence 
closure. Successful RSM results will give more confidence in high-swirl simulations than either $k-\epsilon$ or RNG-based results. Additional work should be done to verify the accuracy of the transient simulations. 
References

Coffee, T. P., 1985, "On Simplified Reaction Mechanisms by Oxidation of Hydrocarbon Fuels in Flames by C. K. Westbrook and F. T. Dryer", Combustion Science and Technology, Vol. 43, pp. 333-339.

Fluent, Inc., 1995, "ELUENT User's Guide", March, 1995, Fluent, Inc., Lebanon, NH.

Glassman, I., 1977, Combustion, Academic Press, New York, NY, pp. 11 .

Hautman, D. J., Dryer, F. L, Schug, K. P., and Glassman, I., 1981, "A Multiple-Step Overall Kinetic Mechanism for the oxidation of Hydrocarbons", Combustion Science and Technology, Vol. 25, pp. 219-235.

Westbrook, C. K., and Dryer, F. L., 1981, "Simplified Reaction Mechanisms for the Oxidation of Hydrocarbon Fuels in Flames", Combustion Science and Technology, Vol. 27, pp. 31-43.

14 
Table I. UTSI MASB: Comparison of measurement to prediction without backwall holes.

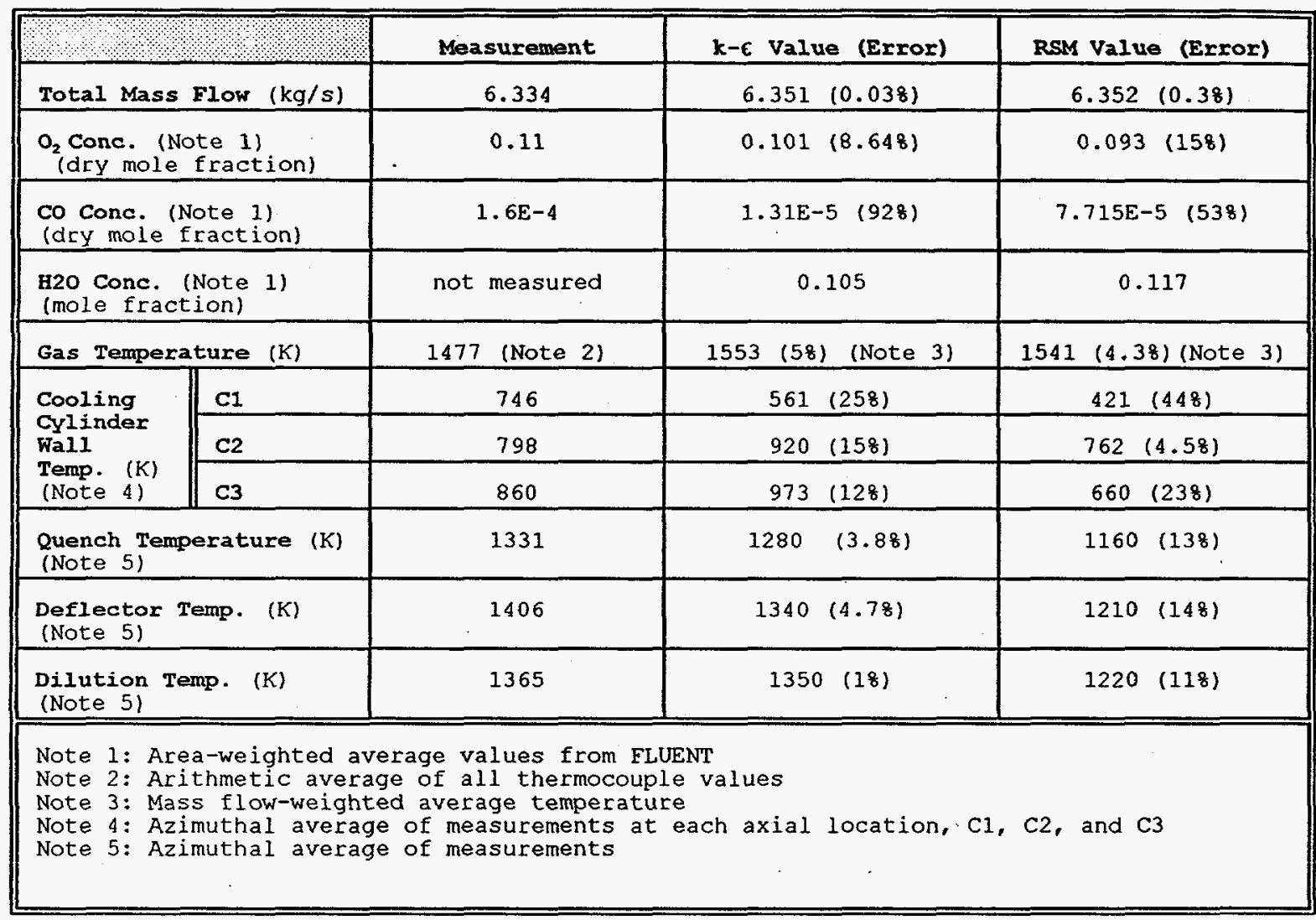


Table II. Comparison of Predicted and Calculated Air Flows for operating Point $A$, cold flow.

\begin{tabular}{|c|c|c|c|c|c|c|}
\hline & & & \multicolumn{4}{|c|}{ Operating Point A: COLD FLOW } \\
\hline & & & $\begin{array}{l}\text { Calculated } \\
\text { by } \\
\text { Westinghouse }\end{array}$ & $\begin{array}{c}k-\epsilon \\
\text { FLUENT } \\
\text { Prediction }\end{array}$ & $\begin{array}{l}\text { RNG } \\
\text { ELUENT } \\
\text { Prediction }\end{array}$ & $\begin{array}{c}\text { RSM } \\
\text { FLUINNT } \\
\text { Prediction }\end{array}$ \\
\hline \multirow{4}{*}{$\begin{array}{l}\text { Cooling } \\
\text { Air } \\
\text { Flow }\end{array}$} & \multirow[t]{2}{*}{ Cone } & Flow $(\mathrm{kg} / \mathrm{s})$ & $1.429 \mathrm{E}-2$ & $1.692 \mathrm{E}-2$ & $1.701 \mathrm{E}-2$ & $1.656 \mathrm{E}-2$ \\
\hline & & Exrox ${ }^{1}$ & & 188 & 198 & 15.98 \\
\hline & \multirow[t]{2}{*}{ cyl. } & Flow $(\mathrm{kg} / \mathrm{s})$ & $5.185 \mathrm{E}-2$ & $4.925 E-2$ & $4.93 E-2$ & $4.96 \mathrm{E}-2$ \\
\hline & & Error ${ }^{1}$ & & 58 & 58 & 4.38 \\
\hline \multirow{6}{*}{$\begin{array}{l}\text { Comb. } \\
\text { Air } \\
\text { Elow }\end{array}$} & \multirow[t]{2}{*}{ Rich } & Flow $(\mathrm{kg} / \mathrm{s})$ & $4.082 \mathrm{E}-2$ & $4.0803 \mathrm{E}-2$ & $3.984 \mathrm{E}-2$ & $3.945 \mathrm{E}-2$ \\
\hline & & Error ${ }^{2}$ & & 0.058 & 2.48 & 3.48 \\
\hline & \multirow[t]{2}{*}{ Quench } & Flow $(\mathrm{kg} / \mathrm{s})$ & $3.81 E-2$ & $3.37 E-2$ & $3.281 \mathrm{E}-2$ & $3.6 \mathrm{E}-2$ \\
\hline & & Errox ${ }^{1}$ & & 11.58 & 148 & 5.58 \\
\hline & \multirow[t]{2}{*}{ Lean 2} & Flow $(\mathrm{kg} / \mathrm{s})$ & 0.2658 & 0.2749 & 0.2763 & 0.2719 \\
\hline & & Error ${ }^{1}$ & & 3.48 & 3.98 & 2.38 \\
\hline \multicolumn{3}{|c|}{ Air Temp. - all flows ${ }^{3}(\mathrm{~K})$} & 349 & 349 & 349 & 349 \\
\hline \multicolumn{3}{|c|}{ Burner Outlet Press ${ }^{3}$ (kPa) } & 101.3 & 101.3 & 101.3 & 101.3 \\
\hline \multicolumn{7}{|c|}{$\begin{array}{l}1 \text { Error is presented relative to the flow calculated by Westinghouse } \\
2 \text { Lean flow is sum of air flow through both dilution swirler and dilution holes } \\
3 \text { Input values specified in ELUENT simulation }\end{array}$} \\
\hline
\end{tabular}


Table III. Description of Start-up Operation: First Five Conditions, $0-31.12$ seconds

\begin{tabular}{|c|c|c|c|c|c|c|}
\hline \multirow{2}{*}{\multicolumn{2}{|c|}{$\begin{array}{l}\text { Operating } \\
\text { Condition }\end{array}$}} & \multicolumn{5}{|c|}{ start-up Operating Point } \\
\hline & & Point A & Point B & Point C & Point D & Point $\mathrm{E}$ \\
\hline \multicolumn{2}{|c|}{ Elapsed Time (s) } & 0.0 & 7.78 & 15.56 & 23.34 & 31.12 \\
\hline \multicolumn{2}{|c|}{ Propane Temperature ${ }^{2}(\mathrm{~K})$} & 300 & 300 & 300 & 300 & 300 \\
\hline \multicolumn{2}{|c|}{ Propane Flow $(\mathrm{kg} / \mathrm{s})$} & $2.223 \mathrm{E}-3$ & $7.484 \mathrm{E}-3$ & $1.515 E-2$ & $3.202 \mathrm{E}-2$ & $5.806 \mathrm{E}-2$ \\
\hline \multirow{2}{*}{$\begin{array}{l}\text { Cooling } \\
\text { Air } \\
\text { Flow } 1\end{array}$} & Cone $(\mathrm{kg} / \mathrm{s})$ & $1.429 \mathrm{E}-2$ & $1.429 \mathrm{E}-2$ & $2.858 \mathrm{E}-2$ & $6.305 E-2$ & 0.1175 \\
\hline & Cyl. $\quad(\mathrm{kg} / \mathrm{s})$ & $5.185 \mathrm{E}-2$ & $5.185 \mathrm{E}-2$ & 0.1039 & 0.2286 & 0.4255 \\
\hline \multirow{3}{*}{$\begin{array}{l}\text { Comb. } \\
\text { Air } \\
\text { Flow }\end{array}$} & Rich $(\mathrm{kg} / \mathrm{s})$ & $4.082 \mathrm{E}-2$ & $4.082 \mathrm{E}-2$ & $8.165 E-2$ & 0.18144 & 0.3357 \\
\hline & Quench $(\mathrm{kg} / \mathrm{s})$ & $3.81 \mathrm{E}-2$ & $3.81 \mathrm{E}-2$ & $7.62 \mathrm{E}-2$ & 0.16783 & 0.313 \\
\hline & Lean $(\mathrm{kg} / \mathrm{s})$ & 0.2658 & 0.2658 & 0.5316 & 1.1703 & 2.182 \\
\hline \multicolumn{2}{|c|}{ Syngas Sweep Air $(\mathrm{kg} / \mathrm{s})$} & $2.087 \mathrm{E}-3$ & $2.087 \mathrm{E}-3$ & $4.173 E-3$ & $9.335 \mathrm{E}-3$ & $1.746 \mathrm{E}-2$ \\
\hline \multicolumn{2}{|c|}{ Air Temp. - all flows (K) } & 349 & 349 & 342 & 373 & 395 \\
\hline \multicolumn{2}{|c|}{ Burner Outlet Press ( $\mathrm{kPa}$ ) } & 101.3 & 101.3 & 101.3 & 120.0 & 224.1 \\
\hline
\end{tabular}


Table IV. Description of Start-up Operation: Second Five Conditions, $38.9-70.0$ seconds

\begin{tabular}{|c|c|c|c|c|c|c|}
\hline \multirow{2}{*}{\multicolumn{2}{|c|}{$\begin{array}{l}\text { Operating } \\
\text { Condition }\end{array}$}} & \multicolumn{5}{|c|}{ start-up Operating Point } \\
\hline & & Point $\mathrm{F}$ & Point $G$ & Point $\mathrm{H}$ & Point I & Point $J$ \\
\hline \multicolumn{2}{|c|}{ Elapsed Time (s) } & 38.9 & 46.68 & 54.46 & 62.24 & 70.02 \\
\hline \multicolumn{2}{|c|}{ Propane Temperature ${ }^{2}(\mathrm{~K})$} & 300 & 300 & 300 & 300 & 300 \\
\hline \multicolumn{2}{|c|}{ Propane Flow $(\mathrm{kg} / \mathrm{s})$} & $8.573 \mathrm{E}-2$ & 0.1216 & 0.1452 & 0.1860 & 0.191 \\
\hline \multirow{2}{*}{$\begin{array}{l}\text { Cooling } \\
\text { Air } \\
\text { Flow }\end{array}$} & Cone $(\mathrm{kg} / \mathrm{s})$ & 0.1833 & 0.2744 & 0.3429 & 0.4808 & 0.4990 \\
\hline & Cyl. $\quad(\mathrm{kg} / \mathrm{s})$ & 0.6645 & 0.9966 & 1.2447 & 1.7418 & 1.8144 \\
\hline \multirow{3}{*}{$\begin{array}{l}\text { Comb. } \\
\text { Air } \\
\text { Flow }\end{array}$} & Rich $(\mathrm{kg} / \mathrm{s})$ & 0.5216 & 0.7847 & 0.9798 & 1.3699 & 1.4288 \\
\hline & Quench $(\mathrm{kg} / \mathrm{s})$ & 0.4899 & 0.7303 & 0.9163 & 1.2791 & 1.3336 \\
\hline & Lean $(\mathrm{kg} / \mathrm{s})$ & 3.402 & 5.103 & 6.3821 & 8.9313 & 9.3486 \\
\hline \multicolumn{2}{|c|}{ Syngas Sweep Air $(\mathrm{kg} / \mathrm{s})$} & $2.735 \mathrm{E}-2$ & $4.11 \mathrm{E}-2$ & $5.144 \mathrm{E}-2$ & $7.225 \mathrm{E}-2$ & $7.53 E-2$ \\
\hline \multicolumn{2}{|c|}{ Air Temp. - all flows $(K)$} & 433 & 470 & 500 & 553 & 560 \\
\hline \multicolumn{2}{|c|}{ Outlet Press. ( $\mathrm{kPa}$, abs.) } & 349.6 & 517.1 & 655.7 & 917.7 & 955.7 \\
\hline
\end{tabular}




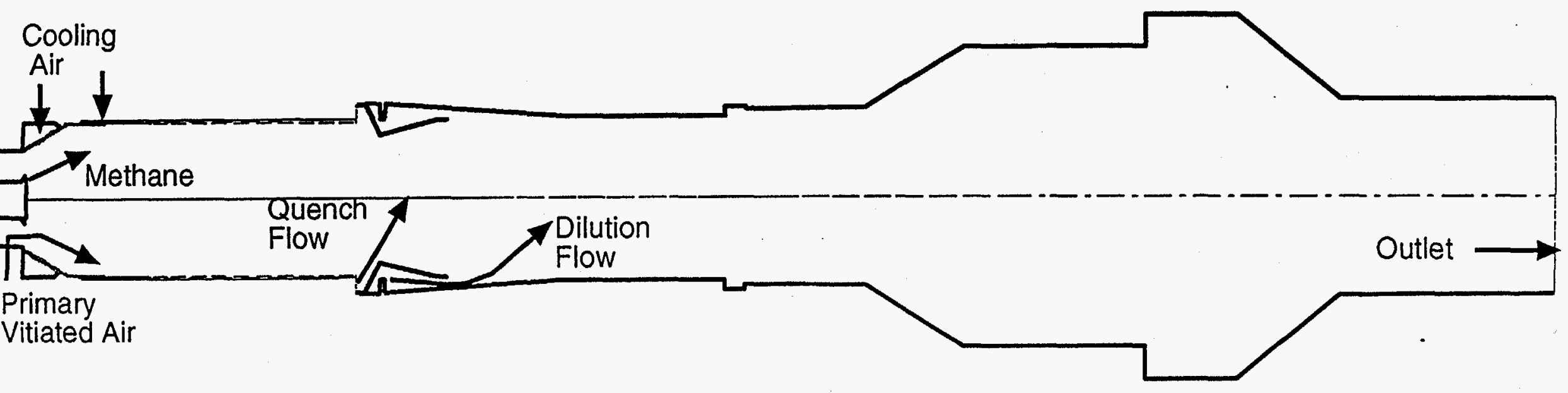

Figure 1. UTSI MASB Computational Domain 


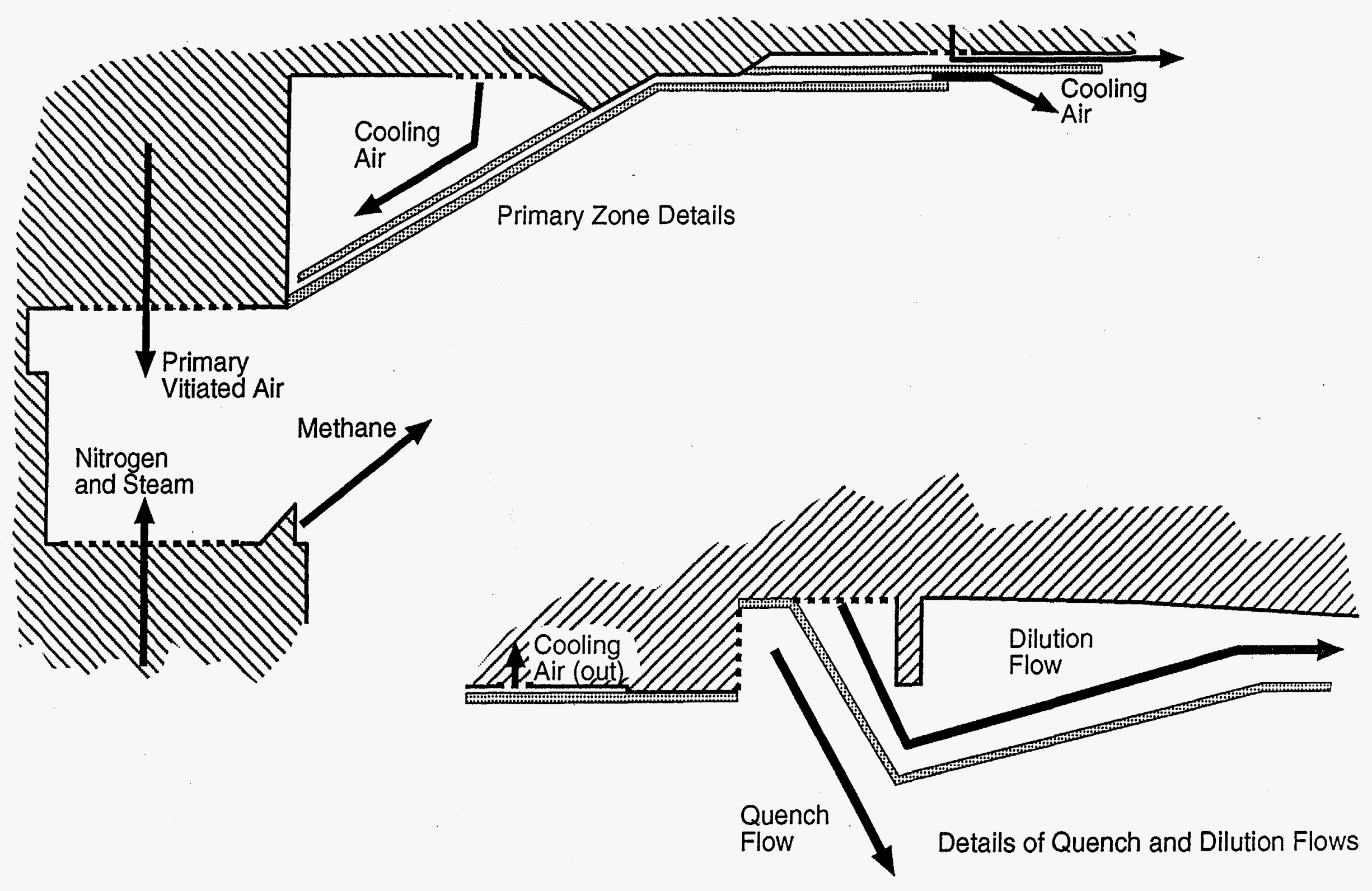

Figure 2. UTSI MASB Flow Details 


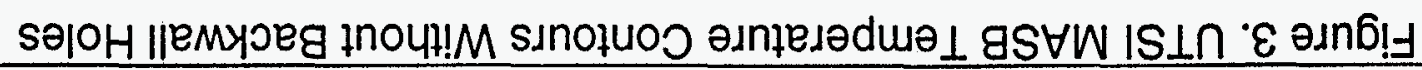
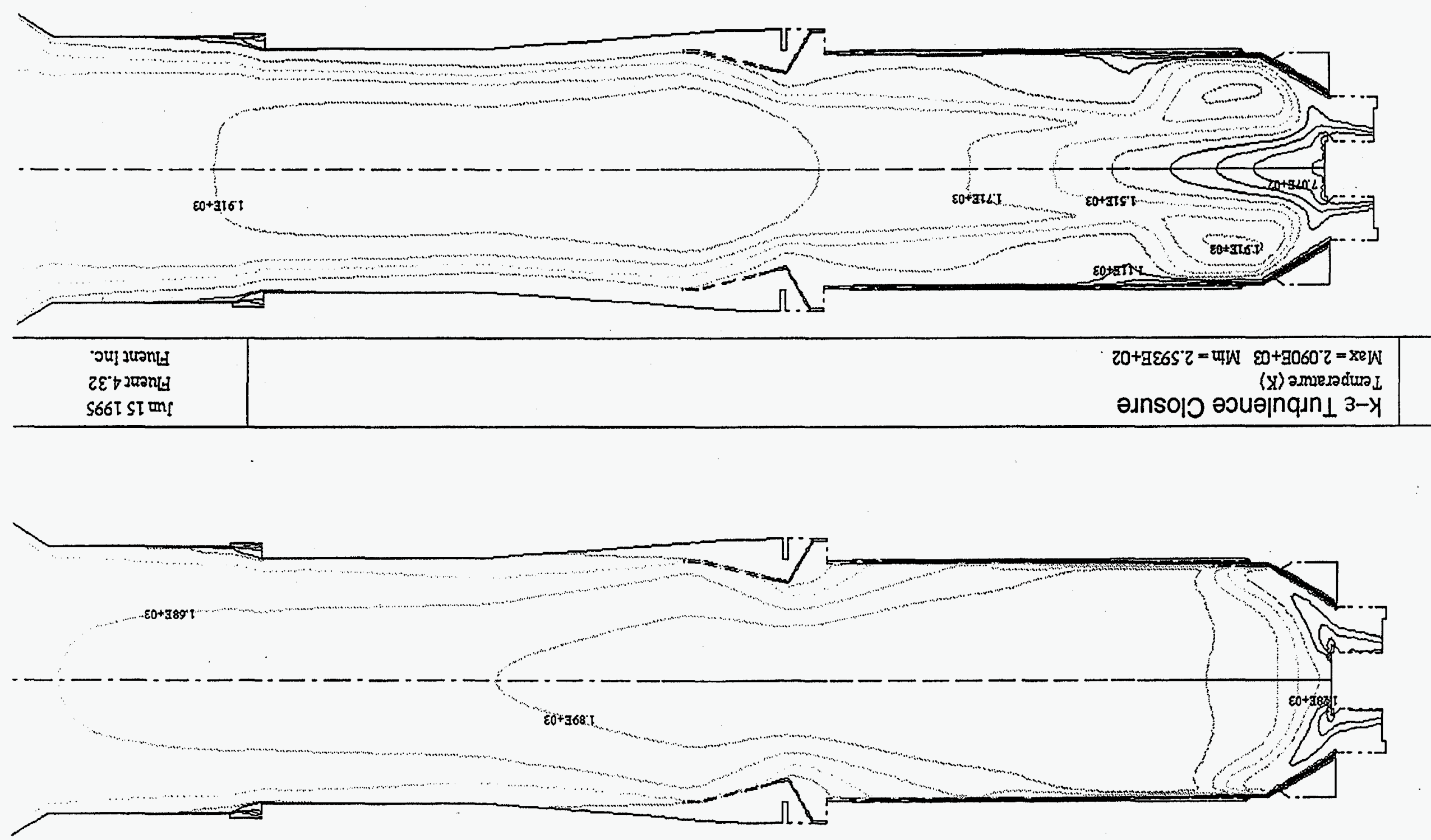


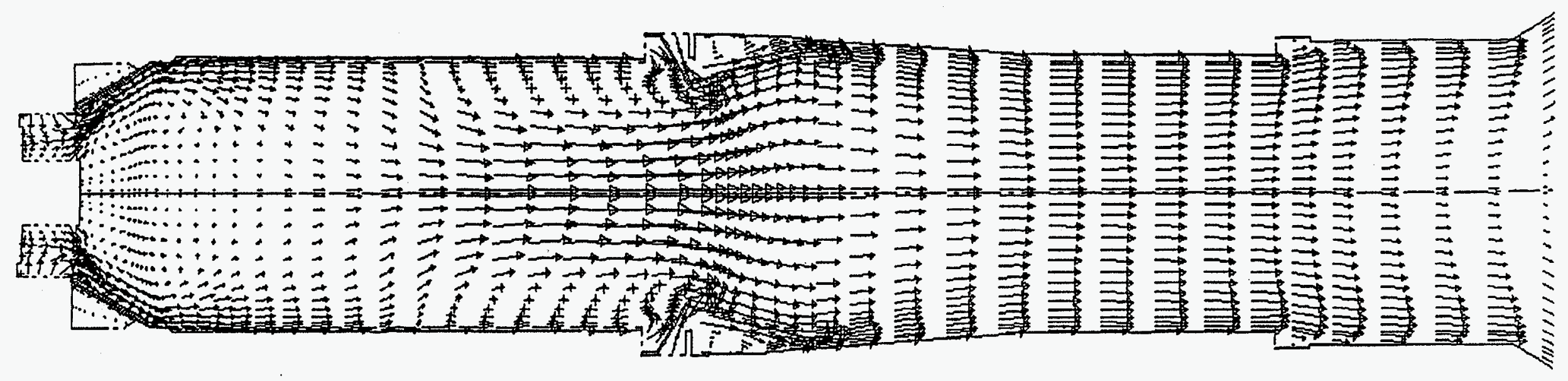

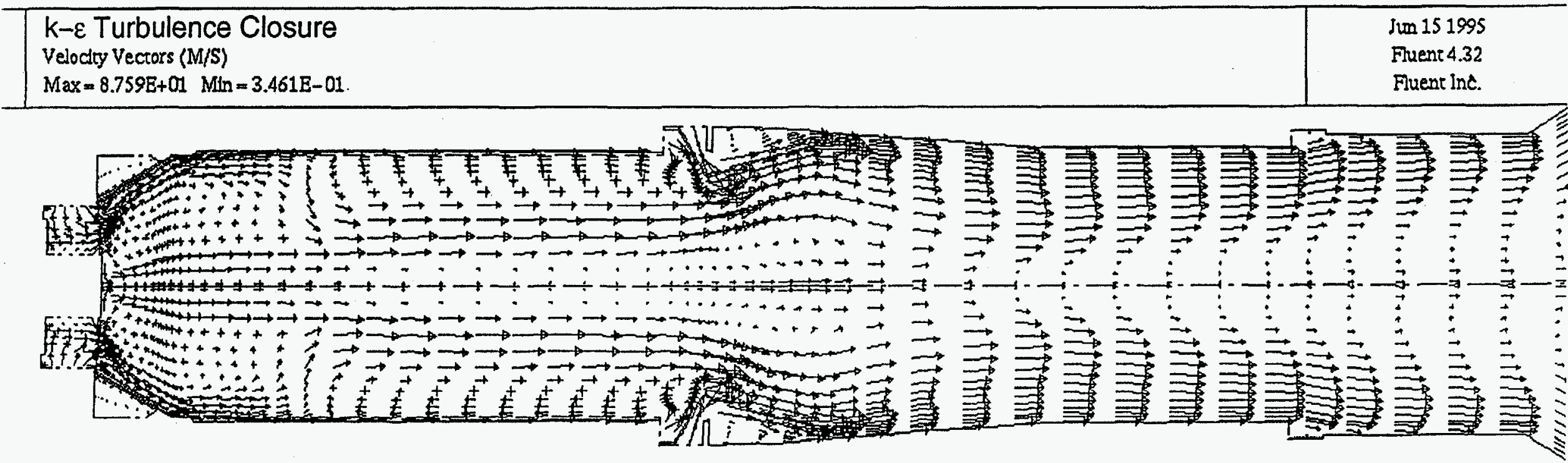

RSM Turbulence Closure

Velocity Vectors $\langle$ M/S $\rangle$

$\mathrm{Max}=8.969 E+01 \mathrm{Min}=4.142 E-01$ 


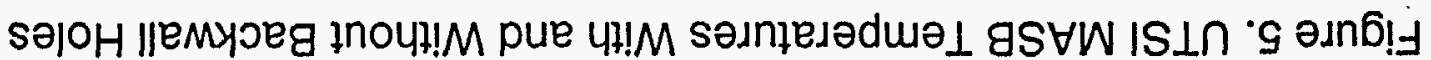
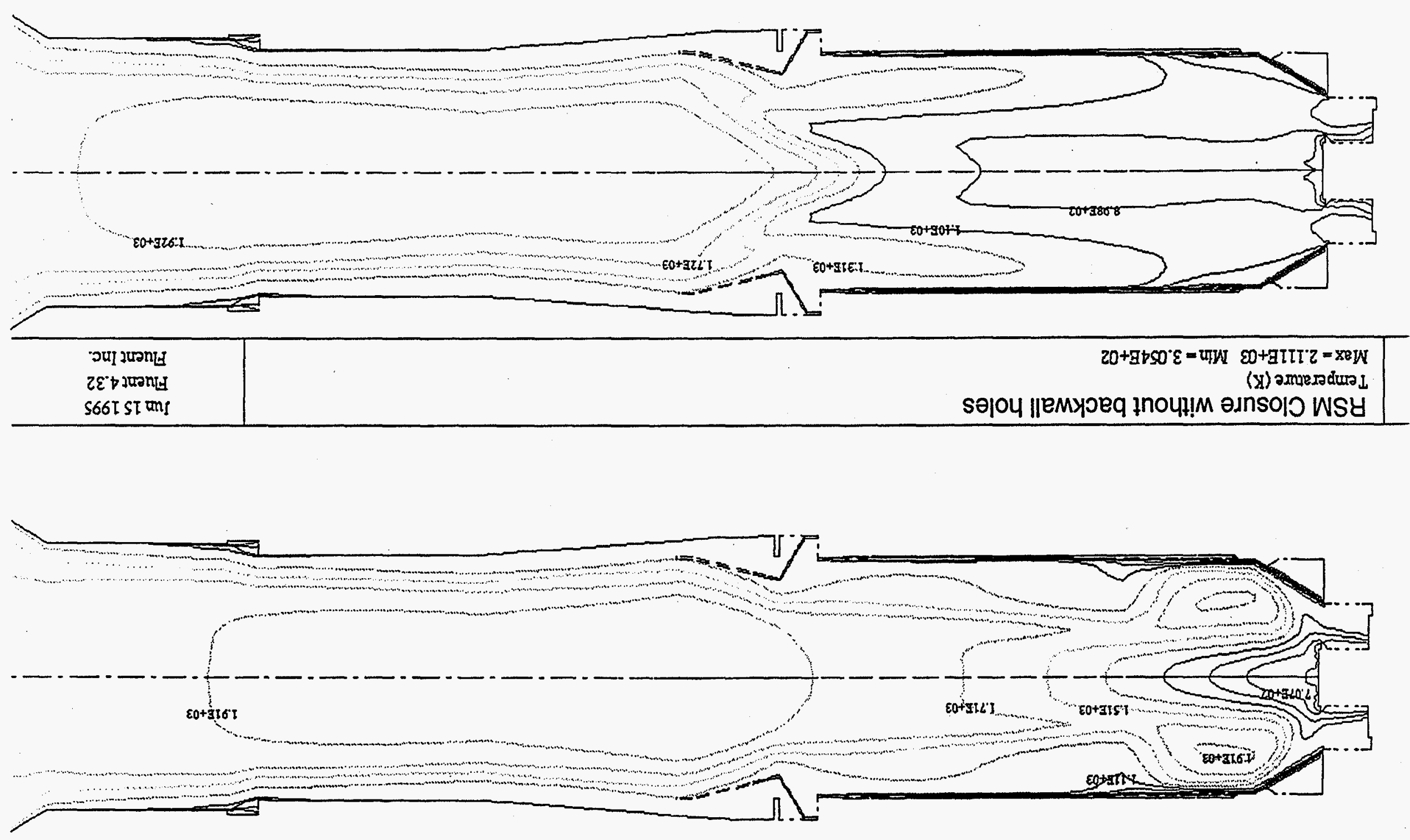

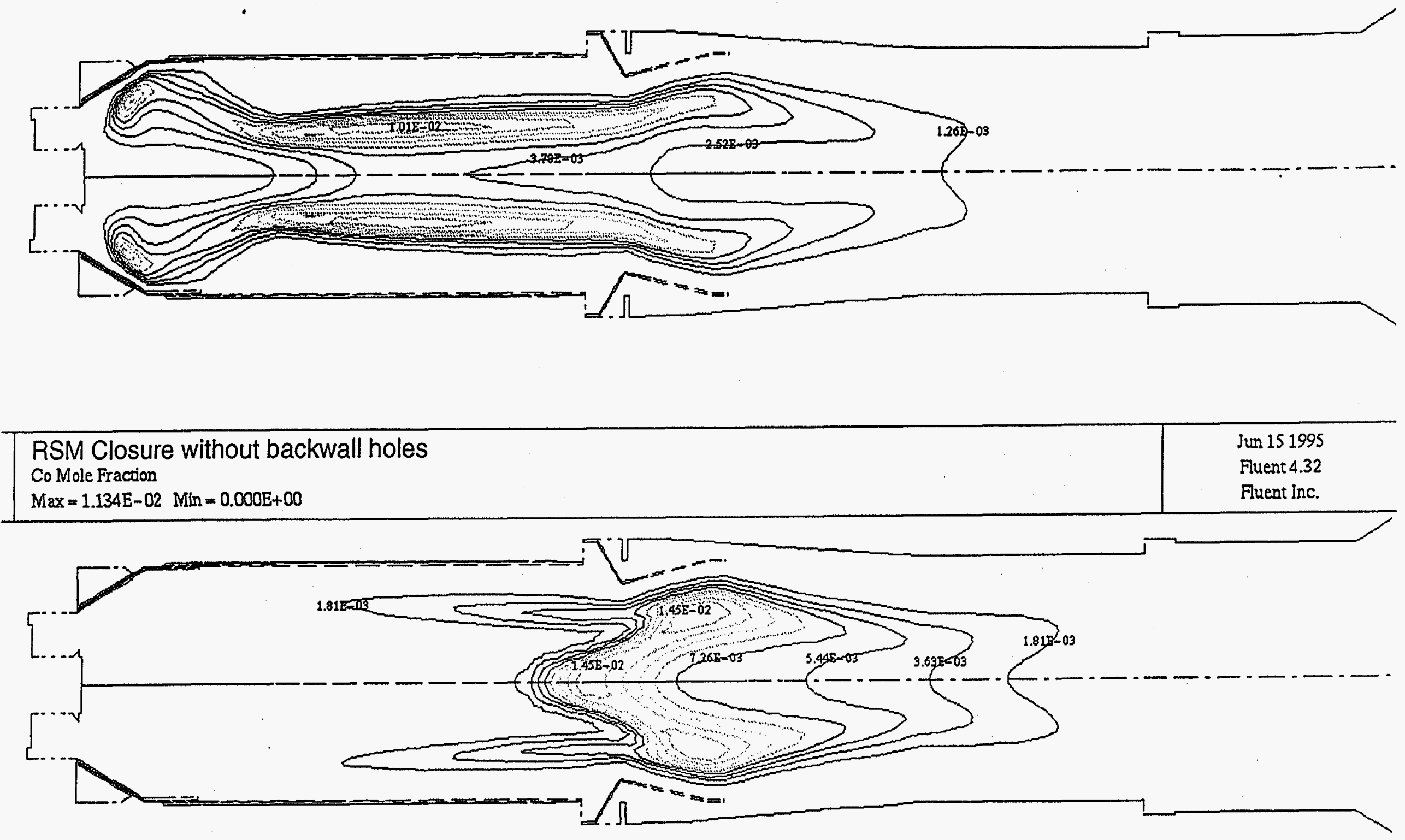

RSM Closure with backwall holes 


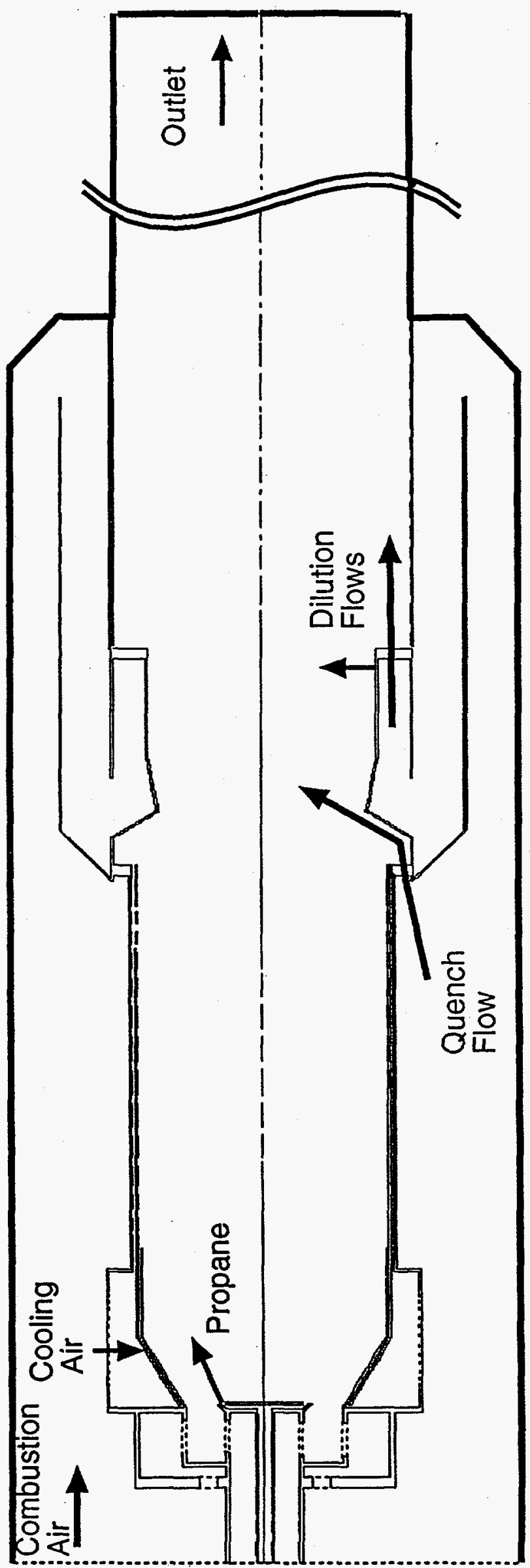

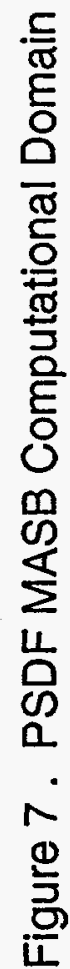




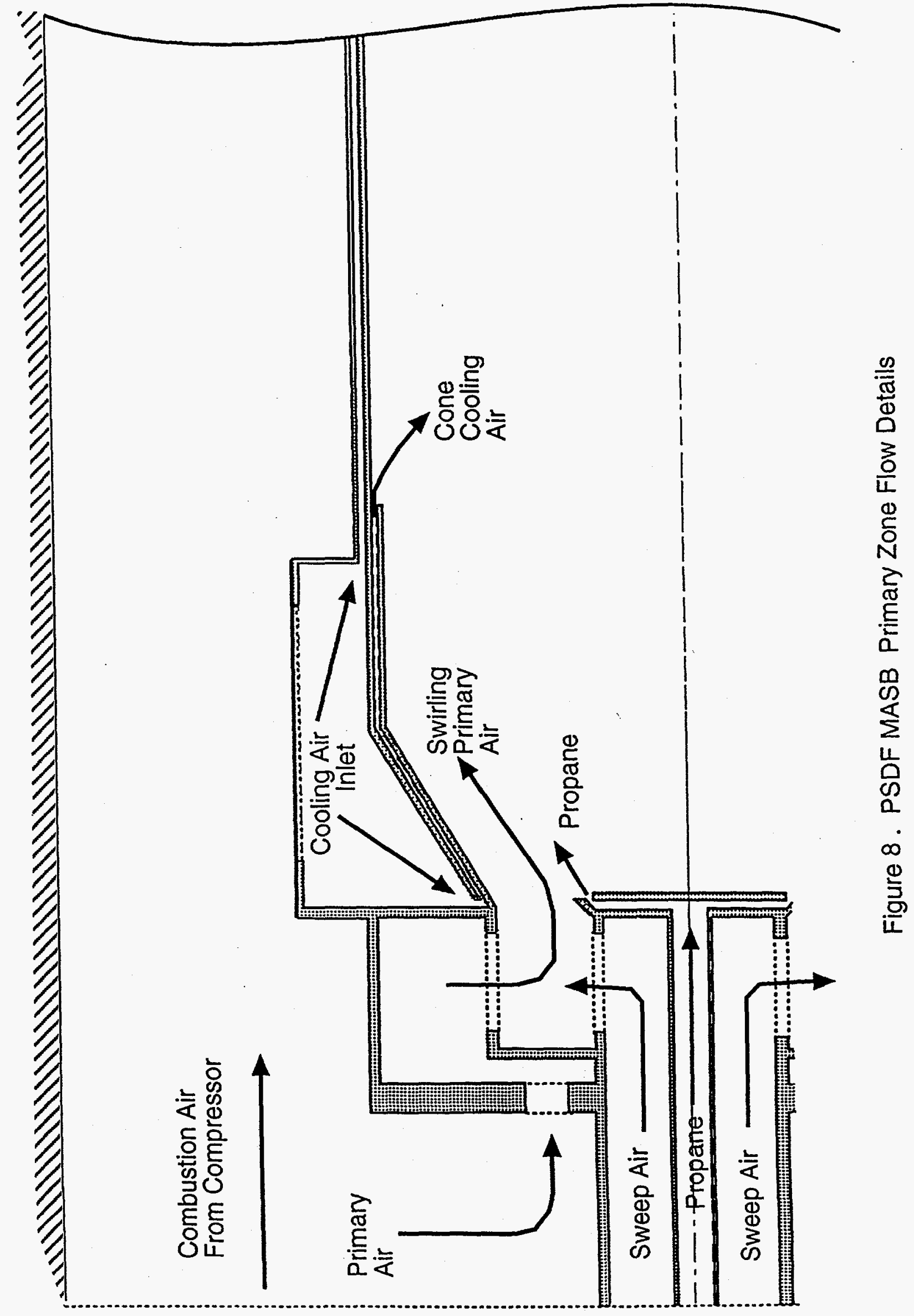




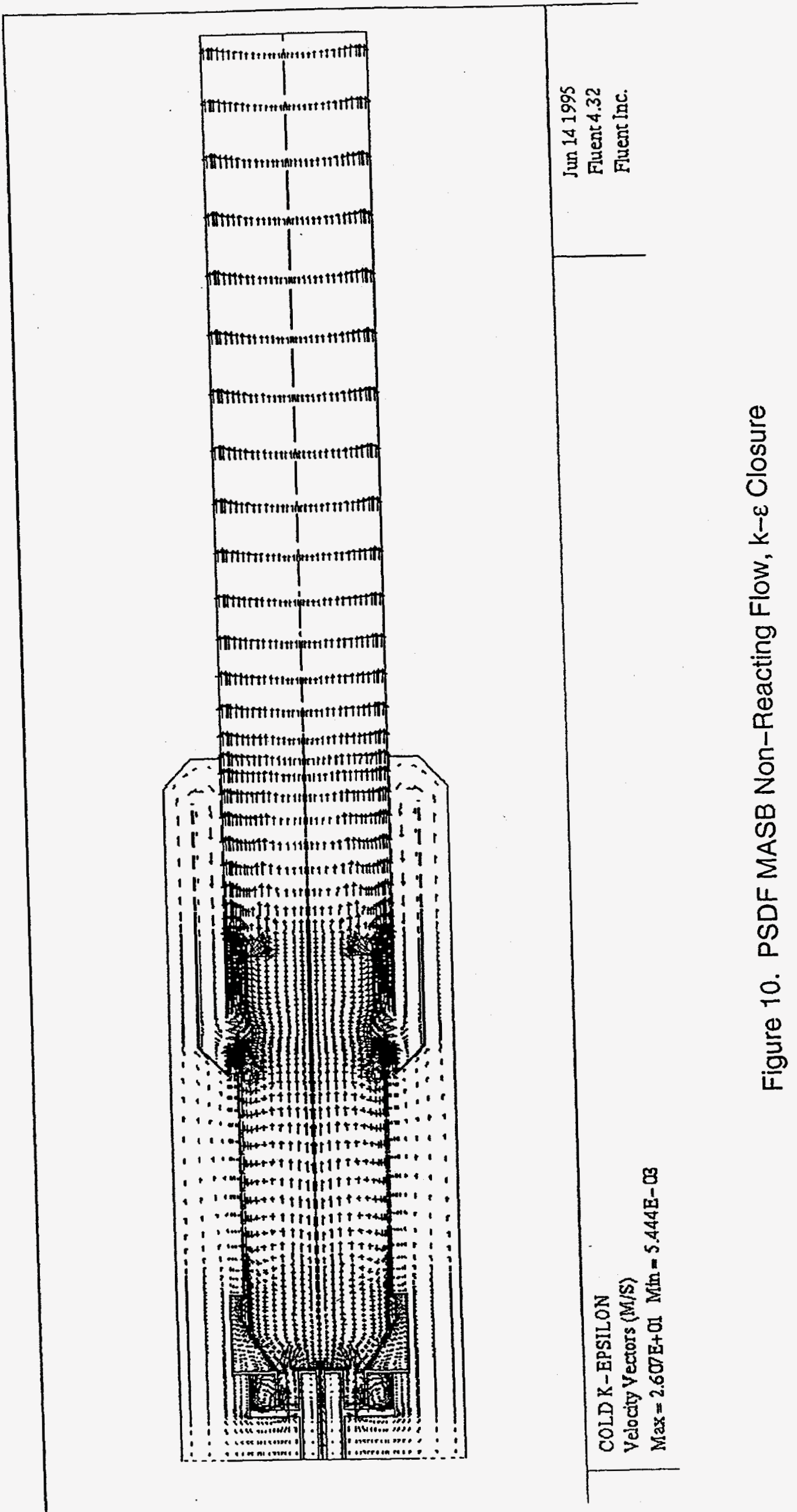




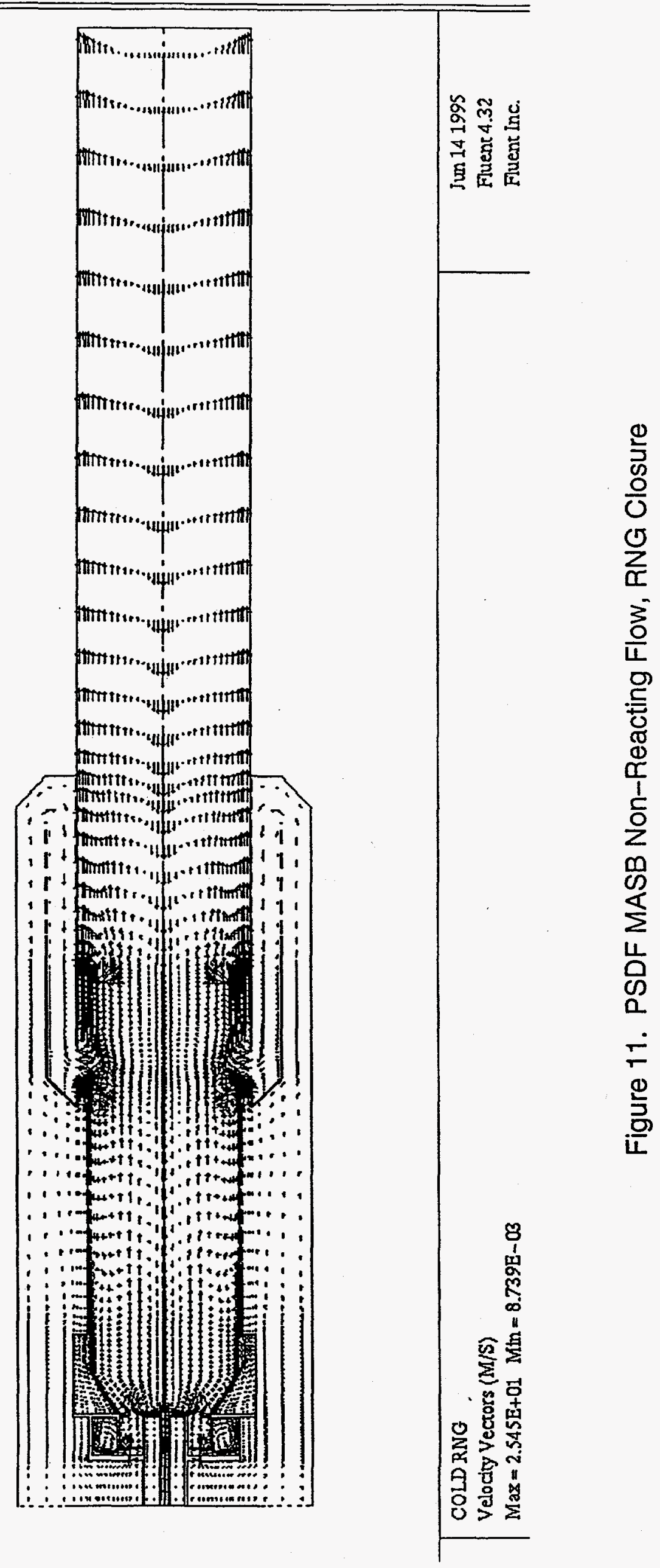




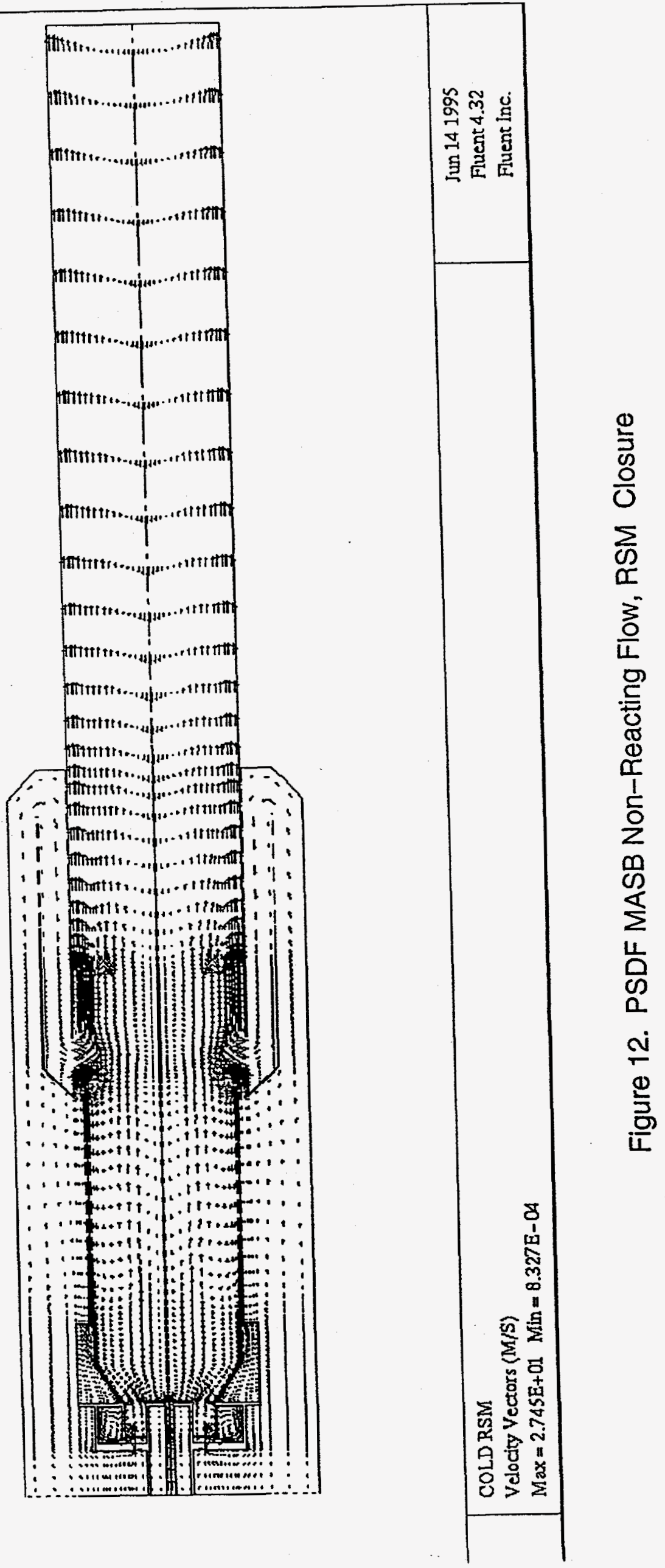



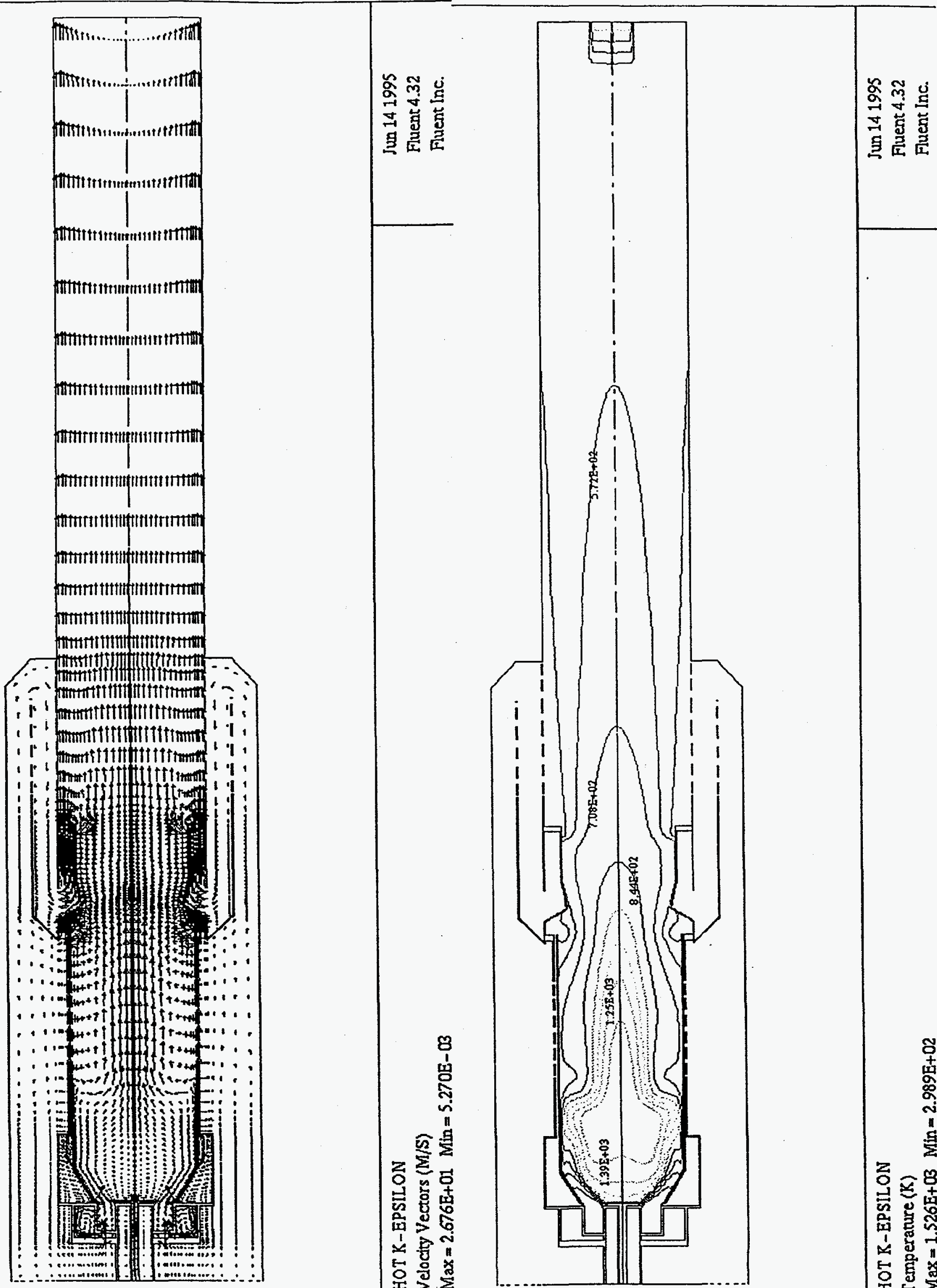

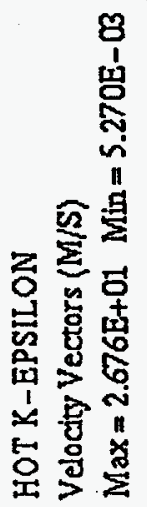




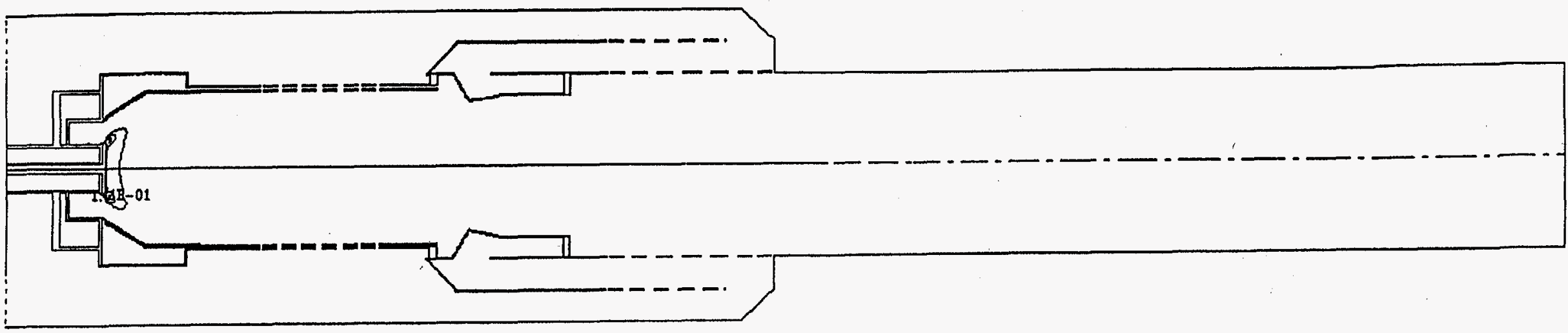

HOT K-EPSILON

C3H8 Mole Fraction

$\mathrm{Max}=1.000 \mathrm{E}+00 \mathrm{Min}=0.000 \mathrm{E}+\infty$

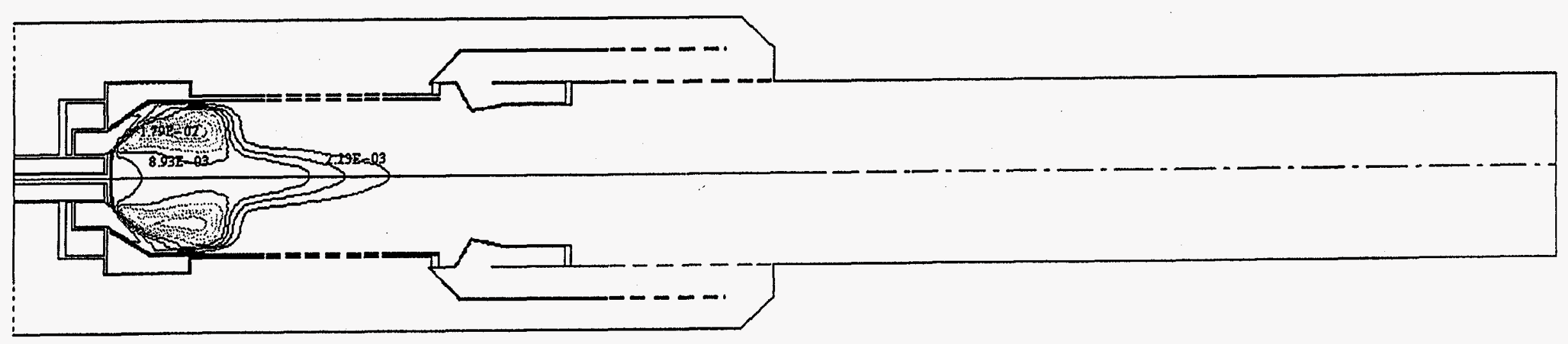




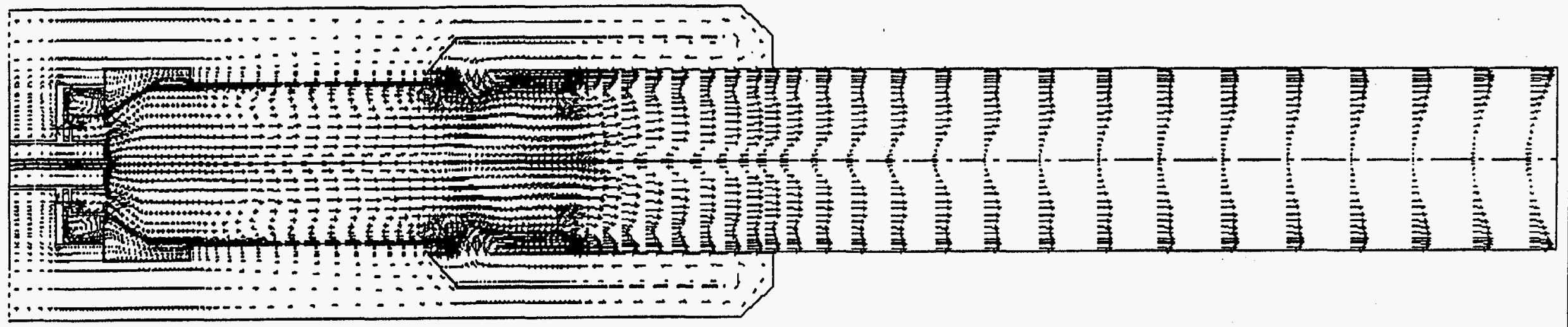

HOT RNG

Velocity Vectors (M/S)

$\mathrm{Max}=2.556 \mathrm{E}+01 \mathrm{Min}=9.007 \mathrm{E}-03$

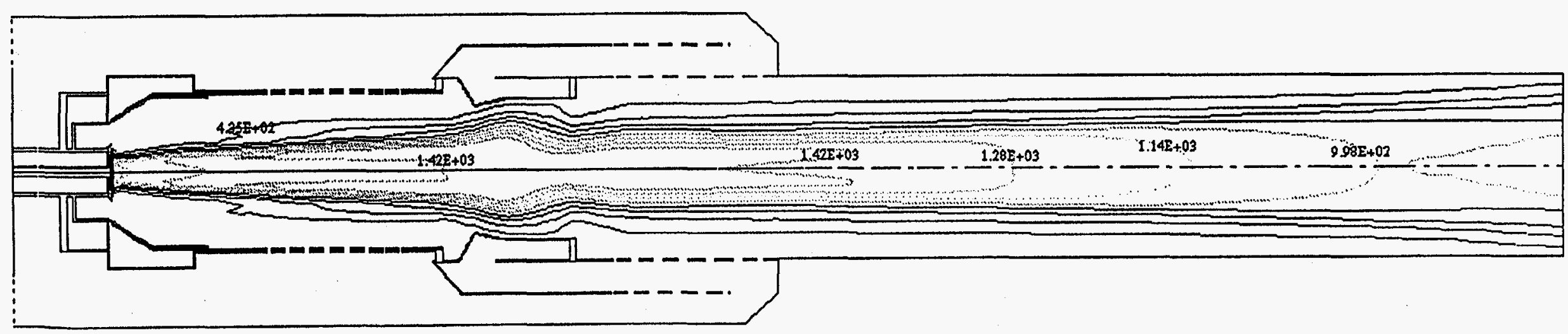




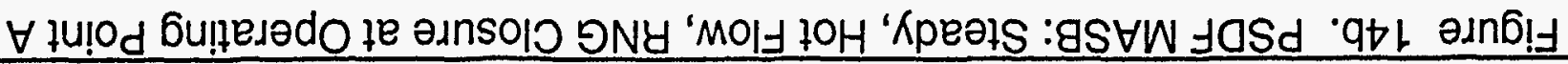
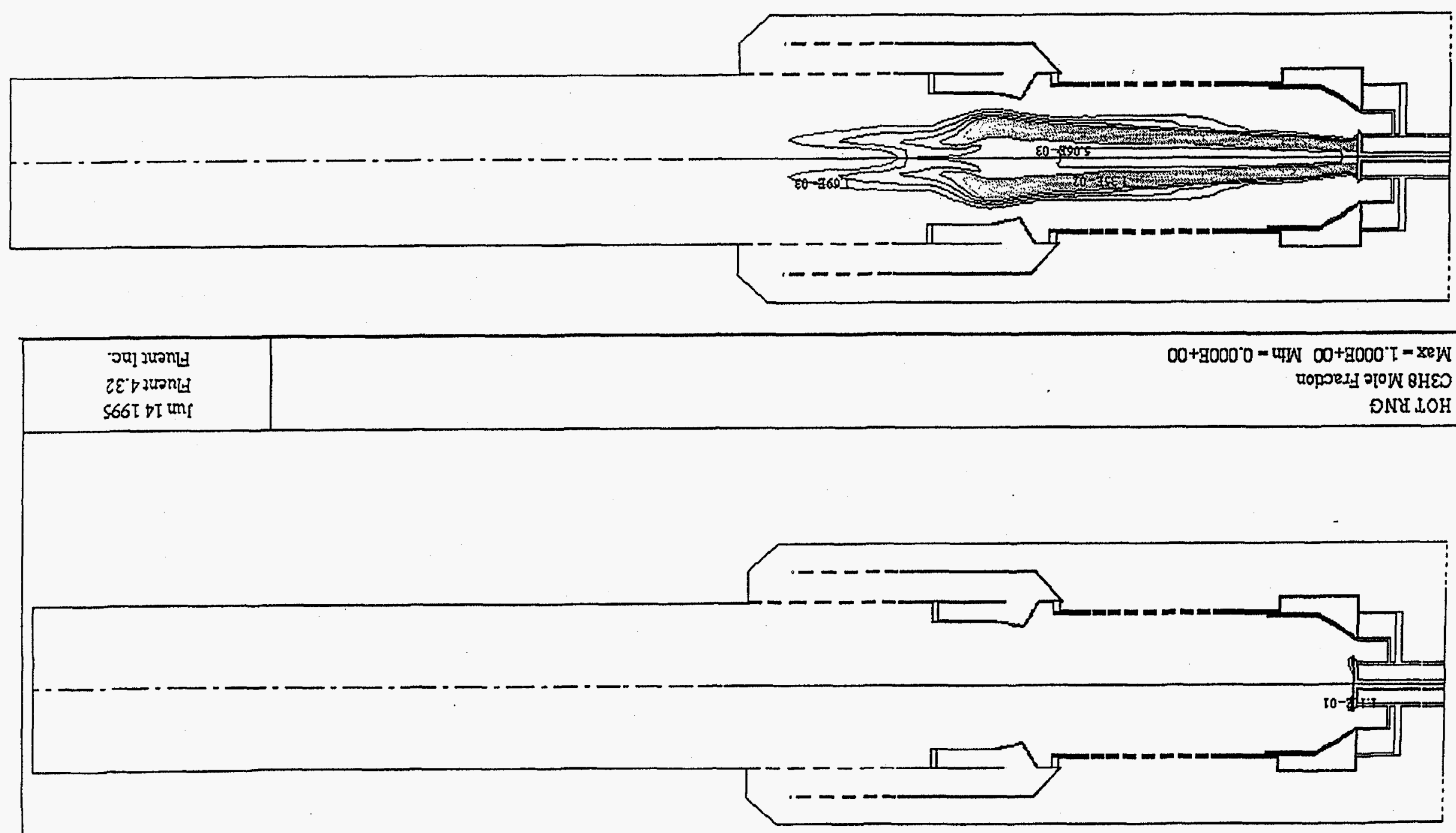


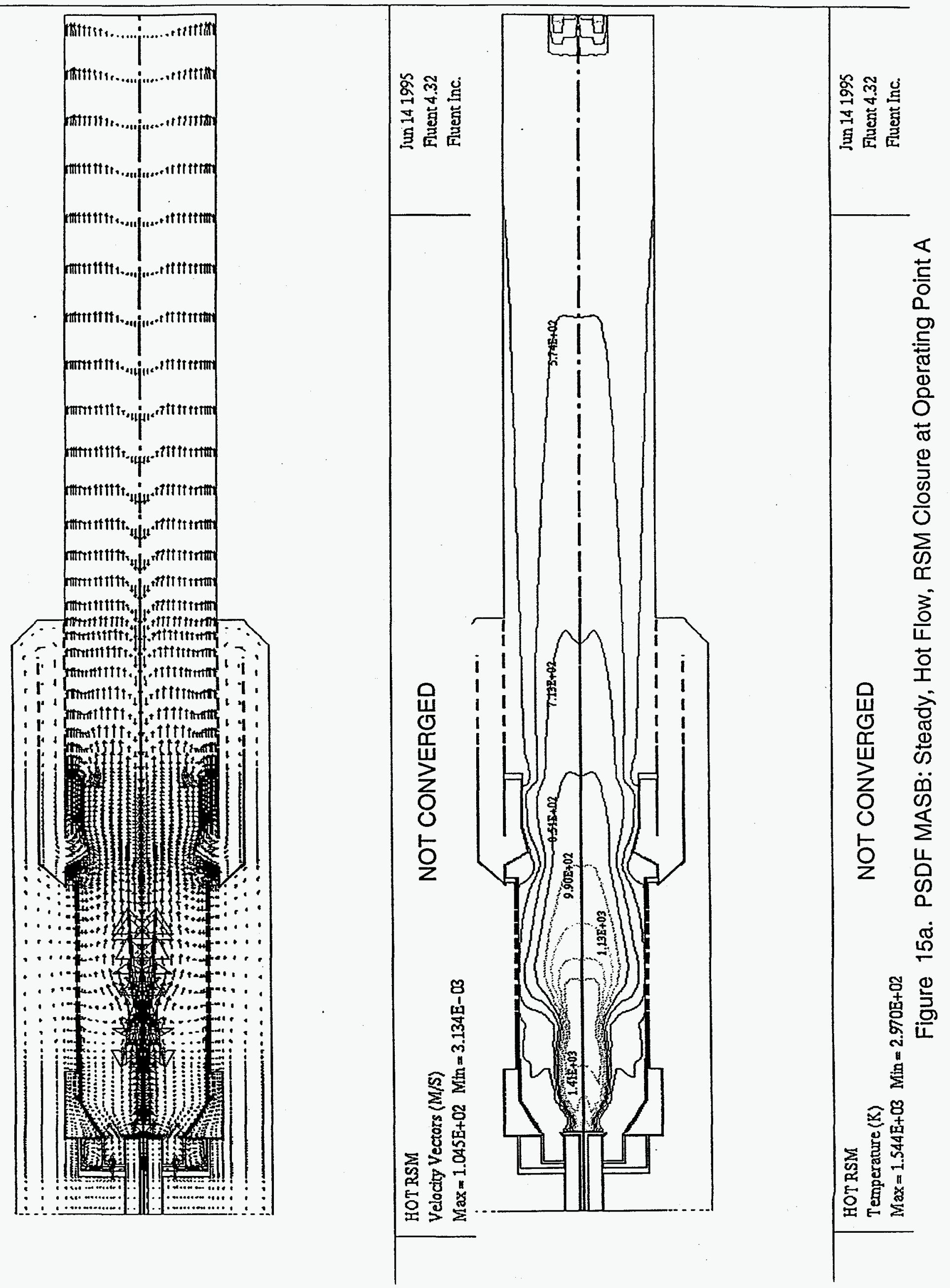




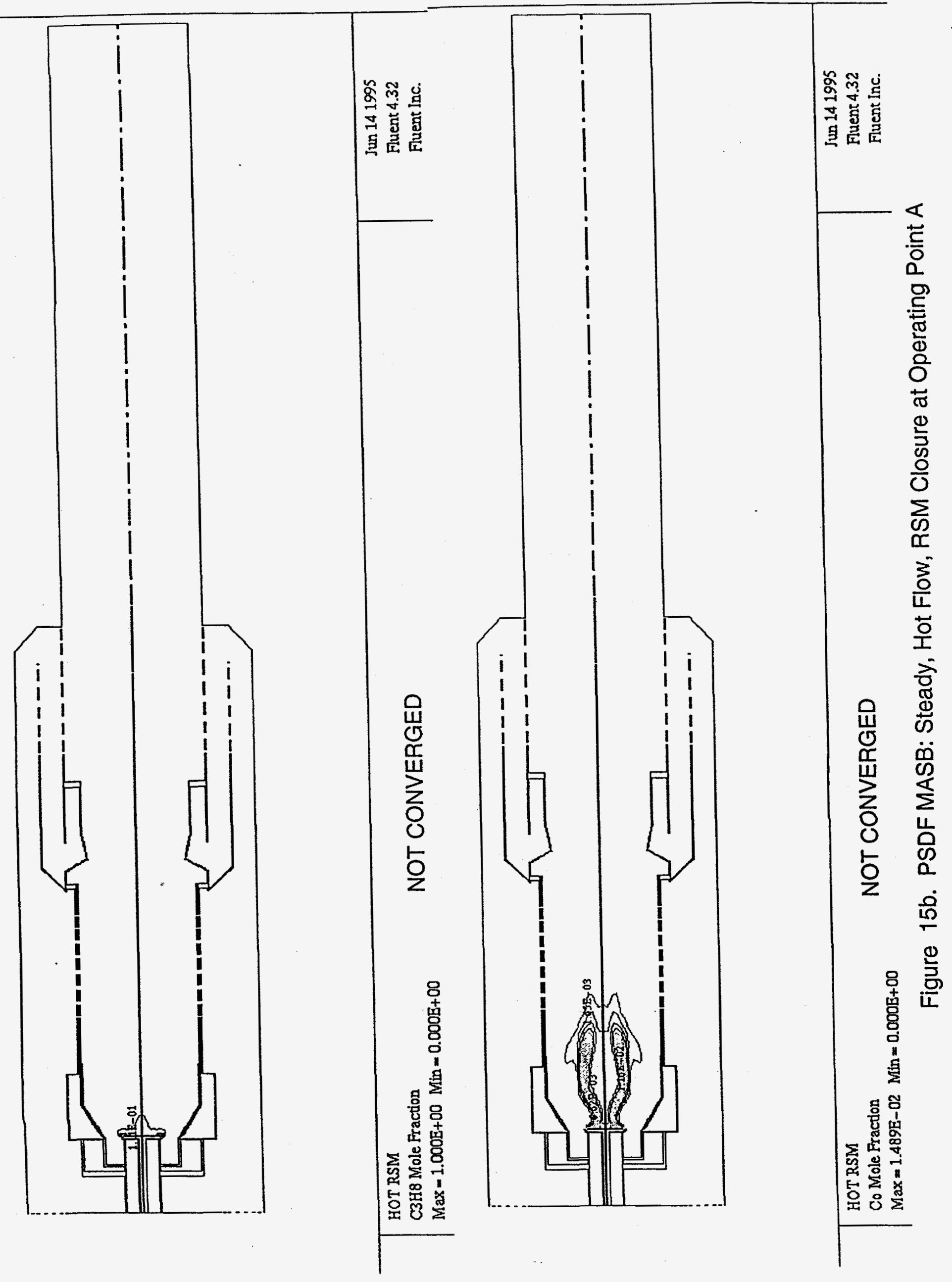




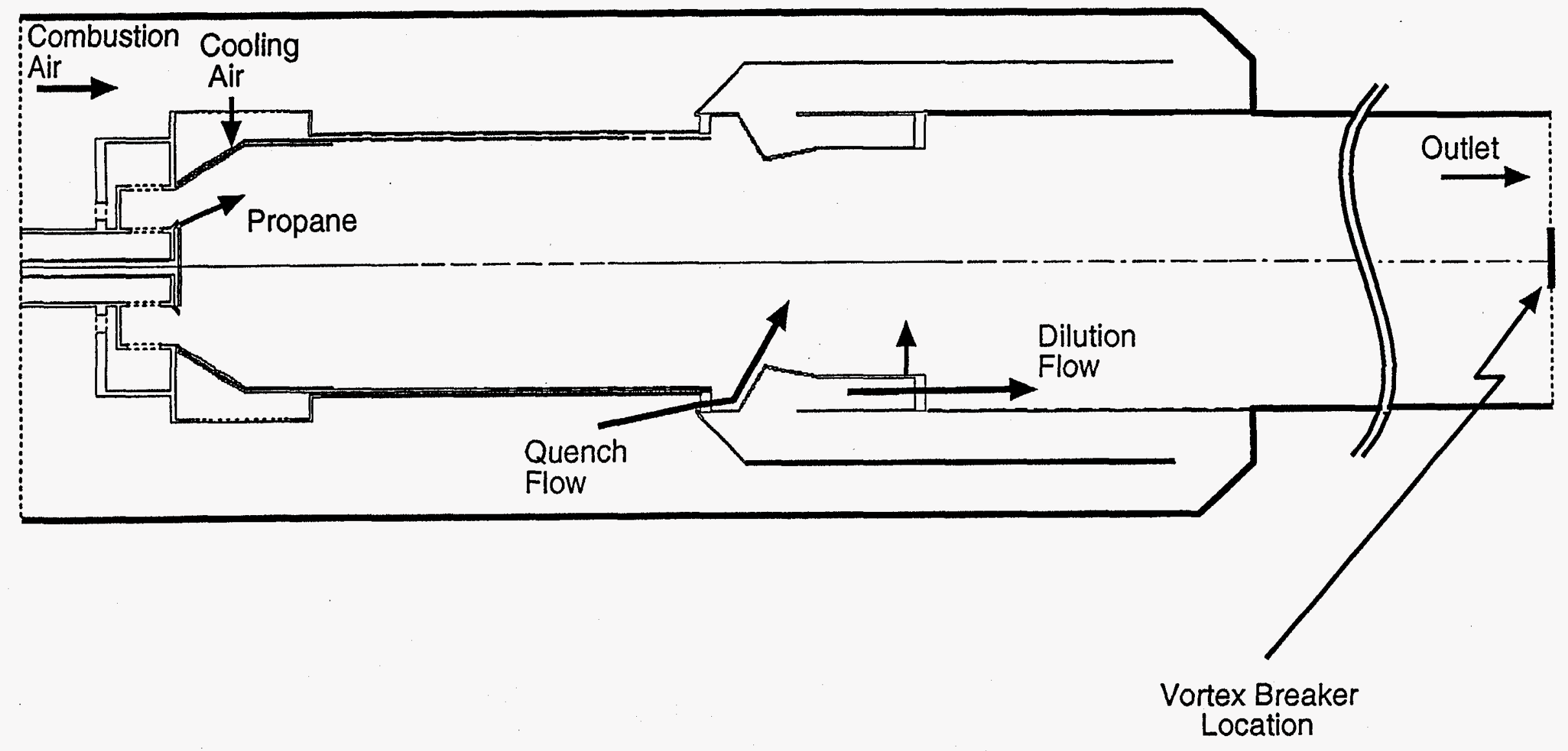

Figure 16. PSDF MASB Computational Domain With Vortex Breaker 


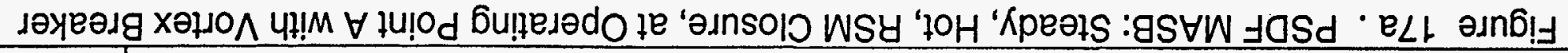

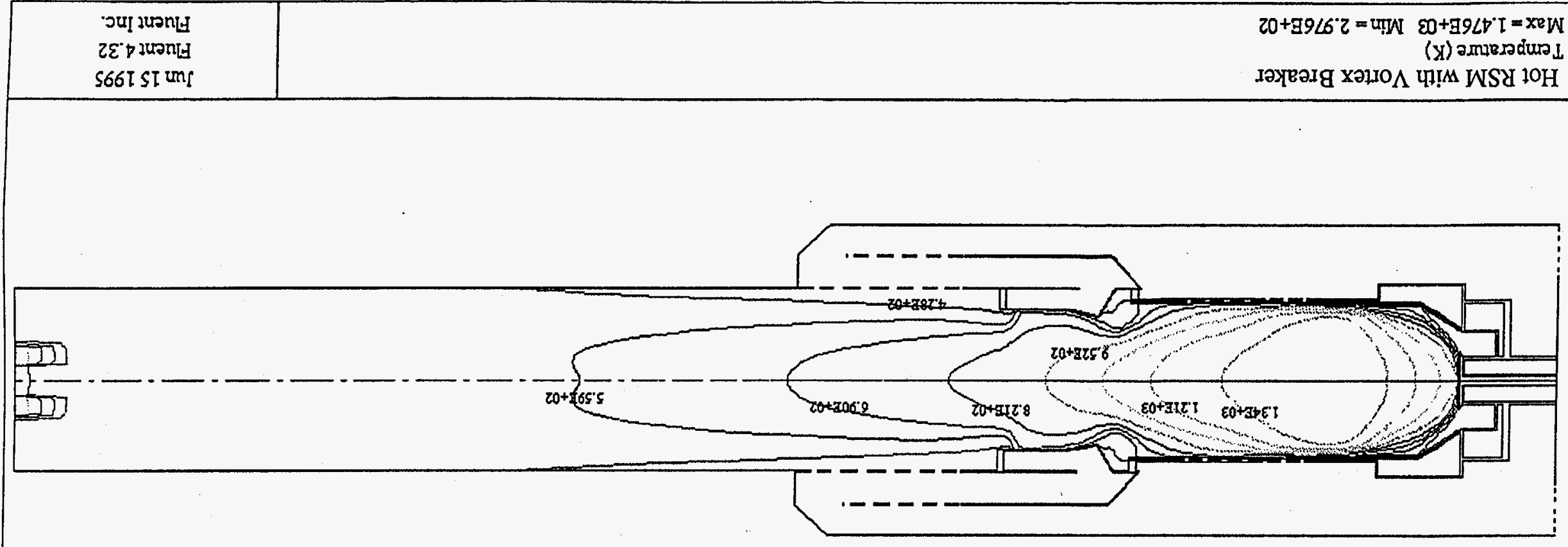

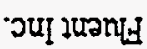

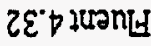

S66I SI ths

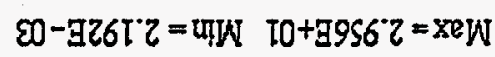
(SiN) SIODDa $\Lambda$ LOP $\Lambda$

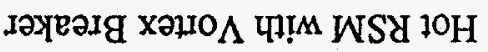

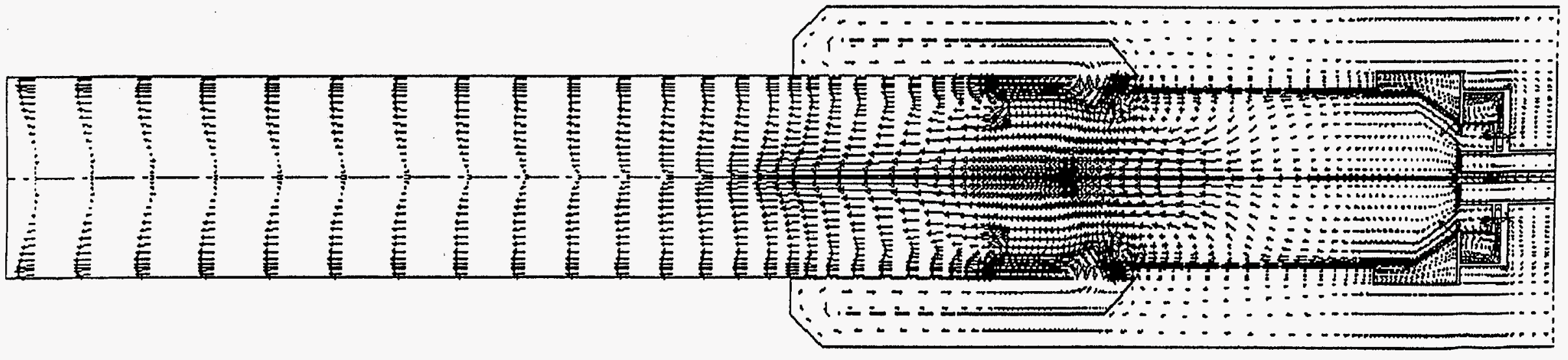




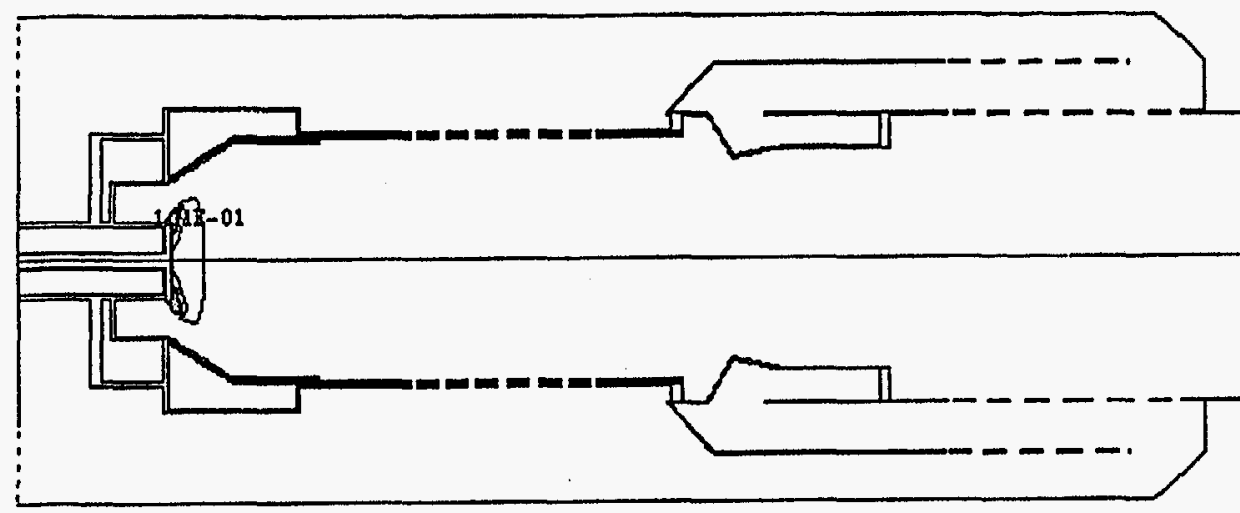

Hot RSM with Vortex Breaker

C3H8 Mole Fraction

$\mathrm{Max}=1.000 \mathrm{E}+00 \mathrm{Min}=0.000 \mathrm{E}+00$

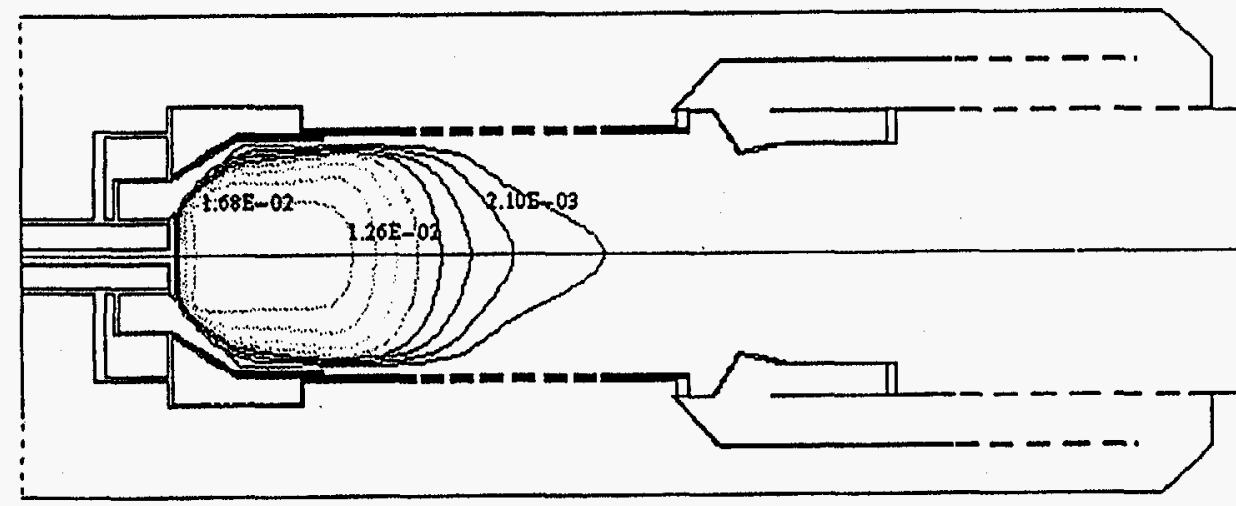

Hot RSM with Vortex Breaker

$\mathrm{Max}=1.887 \mathrm{E}-02 \quad \mathrm{Min}=0.000 \mathrm{E}+00$ 


\section{APPENDIX: CRADA STATEMENT OF WORK}

\section{TASK 1}

Based upon discussions between Westinghouse and METC, Westinghouse will deliver to METC design information as well as experimental results for three configurations of the 18 inch multi-annular swirl burner (MASB). The first two configurations will be the ones tested on natural gas at UTSI, one with and one without back wall holes, and the third will be of the propane startup configuration at the Power Systems Development Facility (PSDF).

Information such as the following is expected:

-MASB geometry

-Elow rates, composition, and temperature at inlets and outlets.

-Estimate of wall temperatures

TASK 2

Using the Westinghouse design data, METC will generate the necessary FLUENT input files to simulate each MASB configuration in two dimensions. Blade and inlet plenum geometry will be considered in these simulations. METC will use these input files to simulate the hydrodynamics and the chemistry occurring within the MASB. Simulations will be performed using both the $k-\epsilon$ and RSM turbulence closures. At the completion of the simulations, Westinghouse and METC will compare all simulation results to available experimental data to determine the accuracy of the predictions.

\section{TASK 3}

As each FLUENT simulation is completed, METC will transfer to Westinghouse in an electronic format satisfactory to both METC and Westinghouse, copies of both the input file and resulting output file.

\section{TASK 4}

METC and Westinghouse will jointly write a final report which will summarize the findings of TASK 2 . 